\title{
Index for Volume 96
}

AUTHOR AND SUBJECT INDEX. Pages indicating errata are in italic.

Abad, G., S87, S134

Abad, J., S1, S59, S87

Abad, Z. A., S1

Abadias, M., S51

Abang, M. M., 1214, S2

Abawi, G. SS44, S176, S178, S182

Abbas, H. K., S2

Abd-Elmagid, A., S2

Abdollahi, K., S25, S157

Abello, J., S59

Abelmoschus esculentus, yellow mottle, Mexico, 1046

Abidou, H., S166

Abler, R. A. B., 926

Abou-Jawdah, Y. A., S32

Abraham, A. D., 437

Abraitis, R., S96

Abramovitch, R. B., S151

Abrams, J., 616

Abutilon theophrasti, control with Colletotrichum coccodes, metallothionein, 1116

Acevedo, M., S2

Acholeplasma spp., genome encodes enzymes, cell wall degradation, S190

Achor, D., S3

Acidovorax avenae

—subspecies genetics, S94

-on watermelon, genetic diversity in China S130

Acosta-Leal, R., S3

Acremonium spp.

-A. implicatum, transformation with Agrobacterium, $\mathrm{S} 59$

-A. zeae, on maize, pyrrocidines, endophyte and pathogen effect, S122

Actinidia chinensis, soft rot, resistance biochemical markers, lyase and chitinase activities, S125

Adams, G. C., S3

Adaskaveg, J., S26, S58, S131, S166, S167, S169

Adeleke, R., S8

Adhikari, T. B., 885, S3, S4, S85, S91, S108

Adkins, S., 460, S3, S188

Aebig, J., S45, S73

Afriyie-Gyawu, E., S152

Agarkova, I. V., 1270, S52, S94

Agindotan, B., S3

Agnew, M., S58

Agrobacterium spp.

-A. radiobacter, on herbaceous perennials, bacterial antagonists, S95

-A. tumefaciens: on Arabidopsis, VirE1mediated resistance, 105; genetic transformation of plants by, interacting protein S5; on herbaceous perennials, PCR detection, S79; salicyclic acid effect, 804; T-DNA integrated into Magnaporthe grisea, S24

$-A$. vitis, on grape and tobacco, hypersensitivity, S178

Agrostis stolonifer

-dead spot: predictive model, S58; severity and overwintering, 248

-defense mechanisms and elicitors, S42

Aguilar, E., S81, S162, S164

Ah Chee, A., S4, S125

Aigbe, S. O., 673

Aime, M. C., S138

Akamatsu, H., 1148, S4, S23

Akimitsu, K., 934

Alameda, M., S162

Albano, J. P., S147

Albertazzi, F., S165

Aldwinckle, H. S., S29, S86, S101, S176, S177, S180, S183

Alexander, N. J., S4
Alfalfa (see also Medicago truncatula)

—disease resistance, persistence, S6

-nematodes and nematode-trapping fungus, interaction, 1388

Alfalfa mosaic virus, on potato, molecular detection, 1237

Alfano, G., S4

Ali, R., S149

Ali, S., 885, S3, S4, S85, S91, S108

Alkharouf, N. W., S104, S191

Allan, N. D., S73

Alldredge, R. J., S23

Allen, C., S25, S36, S128

Allen, T., S4, S5, S94

Allium sativum (see also Onion): fungicides for diseases, Washington, S167

Almeida, M. S., S53

Almeida, R., S5, S14

Alternaria spp., on almond and pistachio, azoxystrobin resistance, California, S71

- A. alternata, on tangerine, fungicide and lesion age factors, $\mathrm{S} 188$

-A. brassicicola, anastomosis and vegetative compatibility, S27

-A. citri, on citrus: histidine auxotroph mutant, cover photo, September; postharvest pathogen, virulence-reducing mutation, 934

-A. dauci, on carrot, diversity and biology, S99

Alvarez, A. M., S58, S89, S119

Alvarez-Ruiz, P., S5, S38

Amaranthus spp., Microsphaeropsis amaranthi for control, climatic constraints, 308

Ambourn, A. K., S57

Amein, A., S2

American Phytopathological Society

—annual meeting abstracts, June supplement, S1

-annual report, 17

-author index of abstracts, S193

—Caribbean Division abstracts, 2005, S162

-Excellence in Extension, 26

-Excellence in Teaching, 27

-Fellows, 19

- International Service award, 28

- Noel T. Keen award, 30

-North Central Division abstracts, 2005, S173

—Northeastern Division abstracts, 2005, S176

—officers, representatives, and committees, 14

-Pacific Division abstracts, 2005, S166

—Potomac Division abstracts, 2006, S190

-publication policies, 2

-Ruth Allen award, 29

- Southern Division abstracts, 2006, S184

—-special session presentation abstracts, S132

- Syngenta award, 31

Amnuaykanjanasin, A., S48

Amylostereum areolatum, woodwasp vector, detection in pine, $\mathrm{S} 123$

Anagnostakis, S. L., S177

Anand, A., 804, S5, S120

Anas, O., S5

Anchieta, A. G., S124

Andersen, M. T., 838

Anderson, J., S151, S156

Andreu, A., S69, S99, S124

Andrews, S., 105

Andrieux, A., S34

Andrivon, D., 777

Andropogon gerardii, rust and drought effect on genes, S37

Angel, C. A., S5

Angelica lucida, virus, novel in Alaska, S98

Angelonia flower break virus

—on Angelonia, cover photo, May

—novel carmovirus, 460
Anguina tritici, on wheat, in U.S. wheat for export, S79

Anikster, Y., S112

Anisogamma anomola, on filbert, geocaching, S170

Ankrah, N. A., S152

Annis, S., S76

Ansari, K. I., S16

Anthony, K. L., S6

Antirrhinum majus, soilborne fungi, pathogenicity in Florida, $\mathrm{S} 188$

Aoun, M., S6

Apampa, K., S112

Aphanomyces euteiches

-population biology, S146

-population genetics, 1134

Aphelenchoides spp., detection method, ornamental crops, S75

Appel, D. N., S157

Apple

-blue mold, biocontrol, S53

-Colletotrichum spp., leaf spot and bitter rot, etiology, 982

-fire blight: blossom age and cultivar effect, S29; cymoxanil, famoxadone, S92; silencing DspEinteracting proteins, $\mathrm{S} 176$

-flyspeck, fungus species cause, S10

-fungal flora, identification, S68

- gray mold and blue mold, postharvest, pyraclostrobin and boscalid for control, S125

- HIPM protein, characterization, S181

—integrated control, Serenade MAX, S48

-Penicillium expansum: fludioxonil- and pyrimthanil-resistant mutants, $\mathrm{S} 67$; and $P$. solitum, factors, S75

— phytoplasma, detection in Mexico, S67

- postharvest decay, methylcyclopropene effect, $\mathrm{S} 100$

- postharvest disease, biocontrol with Pichia anomala, 80

- powdery mildew, milk fat and soybean oil emulsions, S4

-replant site, orchard treatments, S115

-rust, New York, S100

- scab: compost and compost tea applications, S115; epidemic in Pennsylvania, disease management, S118; sanitation treatment, S49

- sooty blotch and flyspeck: apple juice effect, S65; complex in eastern USA, analysis, S29; complex in Germany and USA, S10; complex, identification techniques, S31

-transgenic, disease resistance induced, S18

Apple chlorotic leaf spot virus

- movement protein, interference, 378

—on Nicotiana benthamiana, silencing, S126

Apple latent spherical virus, Bean yellow mosaic virus interaction, mixed infections, fluorescent proteins, $\mathrm{S} 112$

Arabidopsis spp., disease resistance, BONZAH11/ COPINE1 protein, S76

-A. thaliana: bacterial community, salicylic and jasmonic acids, defense, S149; Botrytis cinerea, hypersensitivity, elicitor, 299; crown gall, VirE1-mediated resistance, 105; Magnaporthe grisea, pathosystem, $\mathrm{S} 90$

Aragaki, M., S116

Aranda, S., S37

Arcate, J., S59

Arceuthobium vaginatum, on ponderosa pine, Colorado, S62

Archibald, D. D., S63, S131

Arevalo-Guerra, M. A., S79

Arguello-Astorga, G. R., S77

Arias, C., S87 
Arie, T., 908, S4

Ariss, J. J., S6

Armengol, J., 288

Armillaria spp.: on cherry, distribution in Michigan, S32; on daylily, ITS and IGS-1 sequences, S184; on pine forests, mode of spread, molecular tools, S30; on Pinus radiata, treatment area delineation, 630

-A. ostoyae, on ponderosa pine, wood block traps, S13

Armstrong, C., S6

Armstrong, M., S149

Armstrong, R., S123

Arnold, A. E., S136

Arseniuk, E., S72

Artichoke yellow ringspot virus, on onion, molecular identification and cytopathology, 622

Arul, J., S26

Ascochyta spp., on legumes, specificity and pathogenicity of interspecific hybrid, 1148

-A. rabiei, on chickpea, fluorescent protein, $\mathrm{S} 4$

Asensio, C., 1204

Asensio, M., 320

Ash, J., S66

Asparagus, Xanthomonas translucens, classification of variants, 876

Aspergillus spp.

-A. flavus: on corn, pin bar inoculation, $\mathrm{S} 2$; on corn kernels, aflatoxin, 87; on corn kernels, aflaoxin biosynthesis, S50; on cottonseed, soil factors and rotations, Texas, 599; diploid strain, aflatoxin silencing, S53; oxylipins, determinants, S106

-A. niger, on onion: seedling infection, S106; soil population, $\mathrm{S} 182$

-A. ochraceus, Ochratoxin A biosynthesis, genes, S8

Astragalus utahensis, Aspergillus and Alternaria effect on germination, S32

Astúa-Monge, G., 1092

Asurmendi, S., 1175

Atallah, Z. K., 1037

Atamian, H. S., S32

Austerlitz, F., 280

Austin, C. N., S6

Author index for abstracts, S193

Avant, J. B., S14, S53

Avila, K., S36

Avis, T. J., S6, S7

Ayoubi, P., S93

Aziz, A., 1188

Azpilicueta, A., S164

Babadoost, M., S7, S57, S91, S103

Babbitt, R., S129

Babcock, C., S133

Babina, F. A., S102

Bacetty, A. A., S7

Bacher, S., 813

Bacillus spp.

-B. mojavensis, endophyte, transformation with GFP, S87

-B. subtilis, biocontrol agent, genetic markers, 145

Backhouse, D., S107

Backus, E. A., S7

Bacon, C. W., S7, S87

Bacteria

- coffee and avocado, description, Costa Rica, S162

—-soilless cultures, filter efficiency, S97

— stomatal role in immunity, S77

-virulence and type III effectors, S150

Badillo-Vargas, I. E., S162

Bagci, A., S169

Bai, G.-H., 496, 534

Bai, J., S37

Bailey, A. M., S7

Bailey, D. J., 510
Bailey, W. D., S105

Baker, A. H., S125

Baker, C. A., S3

Baker, C. M., S8

Baker, R. L., S8

Balaji, B., S5

Balci, S., S8

Balci, Y., S8

Baldauf, P. M., S8

Baldo, A. M., S86

Baldwin, M., S190

Balint-Kurti, P. J., 120, 221, 1067

Balogh, B., S53, S98

Balota, M., S94

Banana, Fusarium wilt, symposium, 653

Banana bunchy top virus, molecular epidemiology, Hawaii, S5

Bandyopadhyay, R., 673, S8, S16

Banga, S., S46

Banihashemi, Z., S8, 1046

Barash, I., S85, S122

Barasubiye, T., S41

Barata, R. M., S9

Barbara, S., S4

Barbetti, M., S71

Barker, K., S159

Barley

-Fusarium graminearum, deoxynivalenol quantification, phenotypes, S39

-Fusarium head blight, floret infection, 567

-Fusarium seedling blight, biological control, 386

—rust, race TTKS resistance, $\mathrm{S} 110$

-scald: disease cycle and phases, 1214; fertile crescent not center of origin, diversity analysis, 941

-Septoria speckled leaf blotch, resistance, molecular mapping, 993

- spot blotch: durable resistance, trait locus, S20; mapping resistance loci, 699; resistance gene Rpg1, S12

Barley mild mosaic virus, Korean-Naju strains, S56

Barley yellow mosaic virus, Polymixa graminisinfested soils, S52

Barnes, C. W., S9, S173

Barney, W. P., S114

Baron, J. J., S16

Barrès, B., S34

Barreto, E., S38

Barreto, F. A., S113

Barszcz, E., S179

Bartz, J. A., S9

Bar-Yosef, B., 771

Basim, E., S9

Basim, H., S9, S128

Bassett, C. L., S86

Bastianel, M., 1092

Bastien, M., S10, S52

Bateman, A. M., S10

Bates, C., S10, S173

Bates, G. D., S10

Batzer, J., S10, S29, S31, S64, S65, S122

Baudoin, A., S190

Baum, M., 1214, S2

Baumgartner, K., S10

Baysal-Tustas, F., S11

Bazzini, A. A., 1175

Beachy, R. N., 1175, S109

Beam, R. D., S62

Bean, T. P., S11

Beas-Ruvalcaba, K., S74, S94

Beattie, G. A., S122

Beaulieu, C., S36

Beauveria bassiana, systemic resistance induced in cotton against Xanthomonas, S42

Beck, H. W., S80

Becker, J. O., 111, 855

Beech, mortality in Maine, S59
Beed, F., S79

Been, T. H., 226

Beer, S. V., S176, S179, S181

Beet necrotic yellow vein virus

—allelic discrimination in types, S3

- pathogenicity and species structures, S3

-resistance-breaking isolates, USA, S69

-on sugar beet, crop loss and digital imagery, S56

Beet pseudo yellows crinivirus, on cucurbits, Costa Rica, S96

Beet severe curly top virus, on sugar beet, resistance and insecticide treatments, S111

Beever, R. E., 838

Begomovirus

- movement protein, host factor, S130

- on tomato, PCR for detection, 517

Bejarano-Alcázar, J., 288

Bekal, S., S11, S149

Bélanger, R., S27, S42, S73, S80, S83, S97, S156, S178

Bell, A. A., S11

Bellizzi, M., S118

Belzile, F., S10, S42, S52, S73, S178

Ben-Daniel, B.-H., 417

Ben-Daniel, Y., 417

Bender, C. L., S8

Benhamou, N., S65

Benitez, M., S11, S100

Ben-Joseph, R., 447, 1404

Beno, N., S80

Benson, D. M., S185

Benson, E. C., 828

Benson, J., S20

Benson, M., S42, S87, S126

Bent, A., S111, S159

Bent, E., S167

Bentley, A., S27

Bentley, S., S134, S135

Bentley, T. C., S12

Ben-Yephet, Y., 771

Berardi, R., 709

Berestecky, J. M., S58

Bergdahl, D. R., S178, S182

Bergelson, J., S149

Berger, P., S74, S154

Bergstrom, G. C., 1021, S104, S125

Berkowitz, G. A., S149

Berland, P. A., S114

Bernal, A., S38, S113

Bernard, K., S133

Berner, D. K., S14, S17

Berney, M., S12

Bernier, L., 526, S6, S15, S31, S81, S93, S157

Berruyer, R., 346

Berry, C. L., S12

Berry, S. A., S174

Bertolini, E., 313

Bertrand, P. F., S110

Bérubé, J. A., S137

Betula papyrifera, mycorrhizae, soil factors, S61

Beyer, M., S62

Bezerra, J. L., S12

Bharathan, N., S6

Bharathan, S., S6

Bhat, R. G., S166

Bhattacharya, A., S114

Bienapfl, J., S90

Bigelow, D. M., S170

Bilderback, T. E., S147

Bilgic, H., 699, S12, S20

Biocontainment, questions about, S60

Biofilms fungal, disease role, $\mathrm{S} 73$

Biofumigation, brassica crops, soilborne pathogens, South Carolina, S85

Bioinformatics

—database profiling, PLEXdb, S161

-DNA sequence patterns, new tools, S160

-Fungal Gene Initiative, S161 
—pathosystems biology resources, S161

- phylogenomic exploration, S160

-plant pathology application, genomic data, S160

Biological control

- Alternaria alternata for Plasmopara viticola, grape, 689

- Bacillus licheniformis for Rhizoctonia and Phytophthora, ornamentals, S122

-Bacillus subtilis, genetic markers, 145

—bacteria for broccoli head rot, evaluation, 408

- Colletotrichum coccodes for velvetleaf, metallothionein, 1116

- cotton diseases with Trichoderma virens, mechanism, 178

-Dactylella oviparasitica for Heterodera schachtii, 111

-disease suppression, factors, meta-analytical review, 1168

—factors, meta-analysis, S87

- genetic transformation, agents and methods, S178

-hyphal growth modeling, soil, 1108

- Lysobacter spp., in rhizosphere and phylloplane, nematode effect, S154

- Lysobacter enzymogenes: antibiotics and nematodes, S128; interaction mechanism, S154

-microsphaeropsis amaranthi for Amaranthus spp., 308

-myxobacteria: and gliding bacteria, taxonomy, S153; secondary metabolites, S153

-myxobacterial ecology, S153

-Pichia anomala, on apple, postharvest disease, mechanism, 80

—protein, self-inhibiting, metabolites, S69

-Pseudomonas fluorescens, 2-4-diacetylphloroglucinol production, rhizosphere effect, 751

-rust for Cirsium arvense, weevil transmission, 813

-Trichoderma spp., plant interaction, symposium, 181

-Trichoderma viride: and compost for Allium white rot, 1009; for Sclerotinia sclerotiorum, S164

-wheat and barley to Fusarium seedling blight 386

Biology of plant pathogens, special session, S132

Biopesticide

— challenges in global marketplace, S155

- commercialization facilitated, S156

-Cooperative State Research, Extension \& Education Service role, S156

-EPA role, S156

-forest weed control, targets and problems, S155

-product development, European regulatory hurdles, S156

- university research involvement, S156

— visions vs. reality, S155

Birch, P., S96

Bird, D., S148

Bird, G. F., S173

Bird, G. W., S10, S12

Bithell, S., S167

Blackberry virus $Y$, yellow vein disease, S112

Blair, J. E., 920, S12

Blanchard, A., S149

Blanchette, R. A., 171

Blanco, M., S13

Blankenship, J. D., S34

Blein, J., S80, S140

Blinkova, O., S77

Block, C. C., S35, S107

Blodgett, J. T., S13

Blok, V., S149

Blomquist, C. L., S114, 1416

Blueberry

—epiphytes, enzyme and biocontrol, S57

- mummy berry disease, biocontrol, S76

Blum, K. L., S13
Blumer, S. E., S147, S175

Blumeria graminis, on wheat:

-adult-plant resistance, loci mapping, 784

-Milsana effect on germination and defense, 1278

-resistance gene, 496

— virulence variability in Iran, S96

Blumeriella jaapii

- sterol demethylation inhibitor fungicide resistance, 709

-on tart cherry, copper fungicide effect, S43

Blunt, T., S13

Boal, R. J., S125

Bock, C. H., S13, S14

Bockelman, H. E., S63

Bogdanove, A., S70, S84, S121, S136

Bohlmann, J., S29

Boivin, K., S6

Bolat, N., S166, S169

Bollich, P., S105

Bolognesi, M., 155

Bonants, P., S147

Bonas, U., S135

Bonasera, J. M., S179

Bond, J., S105

Bonde, M. R., S14

Bonello, E., S61

Bonello, P., S34, S119, S157

Bonifacio, A., S112

Bonman, J., S14, S53

Bonos, S. A., 808

Bonsall, R. F., S170

Boonham, N., 975

Boratynski, T. N., S5

Borejsza-Wysocka, E., S86, S176, S180

Borejsza-Wysocki, W. S., S176

Børja, I., 1305

Borneman, J., 111, 855, S167

Borowsky, M., S137

Borrone, J. W., S139

Borselli, S., 689

Borsick, M. A., S14, S176

Borth, W., S14, S77

Børve, J., S110

Bos, J., S4

Bostock, R. M., 1072, 1372, S30, S66

Boston, R. S., S50

Botella, L., 356

Botryosphaeria dothidea, on pistachio, fungicides, $\mathrm{S} 81$

Botrytis cinerea

-on Arabidopsis, elicitor and hypersensitivity, 299

- on grape: chitosan and copper sulfate, 1188; protection by Pythium oligandrum, S80; treatments, S179

—greenhouse crops, silicon-induced resistance, S57

- spread and survival in greenhouse, markers, 1195

Boudon-Padieu, E., 790

Boudreau, M. A., S14

Boulay, M., 1060

Bounds, R. S., S173

Bourassa, M., S34

Bouvet, G., S15

Bové, J. M., 356

Bovill, W., S15

Bowen, K. L., 240, S19, S26, S87

Bowers, J. H., 61, S71

Bowersox, V. C., S9, S173

Boyette, C. D., S15, S121

Boykin, D., S78

Boyle, B., S15

Bradeen, J. M., S15

Bradley, C. A., S60, S123, S126, S173

Bradley, G. G., S15

Branchaw, J., S158

Brandl, M. T., S150
Brannen, P. M., S5, S16

Brantner, J. R., S123

Brar, A. K., S184

Brassica spp.: Alternaria blight, resistance sources, S46; leaf spot, black rot, pathovars, 735; seed meal amendments, apple replant problem, S53

-B. oleracea, head rot, biological control, 408

Brassinosteroids, nodulation autoregulation, role, S88

Braun, H. J., S169

Braun, U., S139

Braverman, M. P., S16

Bredehoeft, M., S56

Bremer, D. J., S37

Bremia lactucae, sporulation, factors, S86

Brendel, V., S70, S136

Brennan, J. M., S16

Brenneman, T. B., S31, S110, S184, S189

Brenneria rubrifaciens, on walnut:

-PCR detection, S75

—pigment production, gene loci, S75

Bressan, A., 790

Breuil, C., 526, S29, S107, S113

Briceno, E. X., S16, S65

Brito, J. A., S182

Britton, M. T., S68

Brlansky, R. H., S101, S163

Brock, J. H., S64, S110

Broderick, K., S128

Brodny, U., 436

Brooks, S. A., S16

Brown, D. E., S94

Brown, D. W., S28, S95

Brown, J. S., S139

Brown, L. G., S16, S79

Brown, R. L., 887, S16

Brown, S. L., S184

Brown, W. F., S61

Browne, G. T., S17, S166, S167

Browning, J. A., 436

Browning, M., S115

Bruckart, W. L., S17, S190, S191

Bruening, G., S35

Brune, P., S17

Brunk, G., S13

Brunner, P., S2

Bruns, H., S2

Bruton, B. D., S79, S130, S188

Bryan, B., S3

Buck, J., S126

Buckles, G., S90

Buechley, G., S28, S91

Buell, C., S17, S160

Bull, C. T., S153

Bulluck, R., S166

Burdman, S., S92

Burkholderia cepacia, on soybean, isolate complex population behavior, $\mathrm{S} 85$

Burlakoti, R. R., S3

Burnes, T. A., 171

Burnett, A. L., S17

Burr, J. A., S19

Burr, T. J., 1230, S113, S177, S178, S179, S180

Burrows, M. E., 828, S127

Buruchara, R., S40

Bushnell, W. R., 567

Busman, M., S95

Bussey, K. E., S184

Butchko, R. A., S95

Butler, E. L., S115

Butterworth, S. C., S174

Büttner, D., S135

Caballero, J. M., 313

Cabrefiga, J., 900

Cabrera, I., S162

Cacao

_black pod, global impact, S138 
-disease management, Papua New Guinea, S62 - disease threats worldwide, S138

-diseases: industry perspective, S139; trilogy, S138

— frosty pod, geographic distribution, S138

—pathogens, phylogenies, S138

-resistance program, marker assisted, S139

- spray deposition analysis system, S177

—vascular-streak dieback, Papua New Guinea S139

—witches'-broom, pathogen diversity, 61

Cacopsylla pruni, vector for "Candidatus Phytoplasma prunorum", European stone fruits, 890

Cadena-Hinojosa, M., S180

Cadle-Davidson, L., S17, S18, S39, S176, S178

Caenorhabditis elegans, genomes, unique nature, S148

Caesar-TonThat, T. C., S140

Cai, G., S18

Caillaud, M. C., 828

Cakir, C., S4

Calabro, J. M., S18

Caldiz, D., S69, S99

Caldo, R., S84, S161

Caldwell, P. M., 804, 1164

Calle-Bellido, J., S162

Calonectria colhounii, koa, Hawaii, S116

Calvert, L. A., S18

Camargo, L. E., S9, S113

Camberato, J. J., S18, S19

Cambra, M., 320

Camellia sasanqua, blight, Colletotrichum gloeosporioides relation, $\mathrm{S} 26$

Cameron, R. K., S150

Camilli, K., S157

Camp, A., S11, S100

Camp, M. J., S51

Camp, S., S111

Campanella, D. M., S18

Campbell, H. L., S19

Campbell, M., S98

"Candidatus Liberibacter asiaticus", on citrus, detection in China, S23

"Candidatus Phytoplasma asteris", gene screening, effector proteins, S192

"Candidatus Phytoplasma australiense", phylogenetic analysis, New Zealand, 838

"Candidatus Phytoplasma prunorum", on European stone fruits, risk factors in survey, 890

Candole, B. L., S19, S184

Candresse, T., S132

Canegallo, A. L., S19

Cannon, E., S161

Cantaloupe (see also Muskmelon), gummy stem blight:

—inoculation technique, S101

- management in Texas, S79

Cao, T., 608

Capote, N., 320

Capsicum spp., Tomato yellow leaf curl virus, symptomless hosts, 447

-C. annuum: Cucumber mosaic virus and Pepper mottle virus mixtures, synergism, 240; Fusarium wilt, biocontrol, S101

Caranta, C., S84

Carbone, I., S1, S13, S94, S98, S138, S160

Carbonell, E. A., 313

Cardenas, E., 1046

Cardina, J., S11

Cardoza, R. E., S116, S165

Cardwell, K. F., S79

Caribbean Invasive Species Surveillance and Information Program, development, S61

Carisse, O., S177, S179

Carlier, A., S119

Carlier, J., S42

Carpane, P. D., S19

Carpenter, D. H., S114

Carpenter, J. L., S19
Carpenter, S. C. D., S179

Carras, M. M., 336

Carroll, J. E., S19

Carrot

- cavity spot, fungicide evaluation, S168

- disease resistance, genetic engineering, S54

- fungal pathogens, resistance and pathogenesisrelated proteins, S119

- pre- and post-harvest disease, Michigan, S103

-rubbery brown rot, Phytophthora root rot, Michigan, S104

Carson, M. L., 221, S14, S20, S27

Carter, M., S71

Cartwright, R. D., S2, S66

Carver, B. F., 496

Casanova, S., S29, S57

Cassava, Fusarium root rot, West Africa, symposium, 673

Castanea sp., blight, sporulation and hypovirulence, 1337

Castañeda-de León, V., S20, S21

Castell-Miller, C. V., S12, S20

Castello, J. D., S181

Castle, A. J., S179

Caswell-Chen, E. P., S128, S154

Catal, M., S3, S57, S174

Catanzaro, C. J., S147

Cattanach, A., S56

Cavin, C. A., S190

Cavins, T. J., S57

Cawly, J. D., S5

Ceccarelli, S., 1214, S2

Celery, late blight, fungicides, tactics and prediction, $\mathrm{S} 173$

Center, T. D., S96

Ceratapion onopordi, rust vector on Canada thistle, 813

Ceratocystis spp.

-C. cacaofunesta, on cacao, $\mathrm{S} 138$

- C. fagacearum, on red oak, nitidulid beetles, Missouri, S47

- C. fimbriata, on taro, Hawaii, S86

- C. resinifera: on conifers, dsRNA viruses, $\mathrm{S} 81$; on spruce, sapstain bioprotection, 526

Cercospora spp.: cercosporin biosynthesis, role in virulence, S141; cercosporin production, related anamorphs, S139; cercosporin production, resistance strategies, S141; on dogwood, cultivar resistance, S26; mating type, genes, S43, S139; speciation and host specificity, S139; on sugar beet, integrated management, S142; on sugar beet, IPM model, S142; on sugar beet, resistance, $\mathrm{S} 141$

-C. beticola: beticolins, chemistry, S140; ecology and epidemiology, S140; epidemiology, new insights, S140; fungicide resistance, S141; fungicide sensitivity, Northcentral USA, S141; fungicides and tolerant cultivars, S142; hosts and fungal antagonists, S140; Integrated Pest Management, quaternary concept, S142; loss prediction, S140; model, leaf spot prediction, S142; model, North Dakota and Minnesota, S142; on sugar beet, hybrids and tolerance, S141; on sugar beet, survival, dispersal, and infection site, S140; resistance breeding, S141; vegetative compatibility groups, S140

-C. cornicola, description revised, S26

-C. kikuchii, on soybean, population genetics, South America and Japan, 1000

-C. nicotianae, cercosporin, resistant and sensitive strains, $\mathrm{S} 48$

-C. zeae-maydis, on maize, resistance components, 593

Cercosporella acroptili, on Russian knapweed, biocontrol, Montana, S191

Cereal

- disease epidemiology, Russia, S102

—rust, detached leaf method, S53 -rust epidemics, epidemiology, modeling, Russia, S102

Ceri, H., S73

Cerqueira, A., S71

Cerra, S. M., S20

Cervantes-Martinez, C., S139

Chabrier, C., 356

Chacon, C. S81, S162, S164

Chacón, G., 777

Chadœuf, J., 890

Chalara elegans, mitovirus, characterization, 468

Chalutz, E., S110

Chambers, A. H., S20

Chambers, D. L., S114

Champoiseau, P., 33, 1081

Chandra-Shekara, A., S20

Chang, C., S21, S23, S192

Chang, P., S72

Chang, S. W., 926, S21

Chapman, S., S149

Charest, J., S182

Chastagner, G. A., S166

Chatelet, D. S., S21

Chatterton, S., S21

Chavarria Soto, E., S165

Chavez-Medina, A., S67, S103

Chávez-Medina, J., S20, S21

Chen, C., S21, S22, S130

Chen, J., S7, S22, S23, S69, S77, S108, S133

Chen, L.-F., S22, 1164

Chen, M., S22

Chen, S., S117

Chen, T. (Tenn.), S104

Chen, T.-C. (Taiwan), 1296

Chen, W., S23, S85

Chen, X. (Canada), 468

Chen, X. (Wash.), S23, S102, S103, S130

Chen, Y., S21, S22

Chen, Z., 87, S16, S22

Chenault, K. D., S23

Cheng, M., S23

Cheon, J., S128

Cherry

-Armillaria root rot, fungal antagonists, S49

- powdery mildew, detection with PCR primers, S168

Cherry green ring mottle virus, Cherry necrotic rusty mottle virus comparison, variability, S68

Chesrown, C. D., S173

Chestnut, blight, hundred years of history, S143

Chhetri, B. P., S3

Chiba, A., 908

Chickpea chlorotic stunt virus, on legumes, new polerovirus, Ethiopia, 437

Chida, T., 378

Chilvers, M. I., 1148, S4, S23

Chinnasri, B., S24, S108

Chiroleu, F., 1345

Chitrampalam, P., S24

Chng, S., S167

Cho, H., S24, S66, S89

Cho, K., S109

Cho, W., S61

Choanephora cucurbitarum, on mango, Mexico, S94

Choi, G., S109

Choi, H., S90

Choi, J., S24, S52, S104, S106, S191

Choi, M., S6

Choi, W., S106

Choi, Y., S24

Chondrilla juncea, biocontrol, multiple organisms, S18

Chong, J., S53

Choppakatla, V., S24

Chorbadjian, R., S34

Choy, K., S14

Christ, B. J., 1157 
Chrysanthemum, stunt viroid, detection using RTPCR, S89

Chun, S., S60

Chung, B., S89

Chung, K.-R., S141, S186

Chung, W., S66

Chunwongse, J., S67

Chuprina, V. P., S102

Church, G. T., S100

Cipollini, D., S34

Cirsium arvense, rust, insect-transmitted urediniospores, 813

Citovsky, V., S5

Citrus

-Alternaria brown spot: fungicides, pre- and post-application, S118; worldwide distribution, S165

-Alternaria citri, postharvest disease, 934

- "Candidatus Liberibacter species", detection, S67

- canker: copper fungicides, S123; image analysis and visual assessment, S13

- exocortis and cachexia viroids, RNA molecules, S118

-leprosies, bipartite RNA virus, S163

-mandarin, rind breakdown, etiology, S26

- postharvest decay: axoxystrobin, S167; fungicides and drenches, S169

- variegated chlorosis, diagnosis, S13

- viroids, trifoliate orange grafts, interactions, 356

Citrus exocortis viroid, on trifoliate orange, Hop stunt viroid co-infection, cover photo, April

Citrus leprosis virus

- cytoplasmic, serological detection, S163

-resistance inheritance, Brazil, 1092

Citrus tristeza virus

—diversity in Hawaii, S77

- genomic sequence, India, S101

- minor coat protein, encapsidated region of genome, $\mathrm{S} 41$

- on Nicotiana benthamiana, DNA sequences and RNA silencing, 819

- population diversity in Florida, S163

- on sweet orange and grapefruit, quantification method, S163

- transgenic grapefruit plants resistant to, S35

Ciuffo, M., 560

Civerolo, E., S22, S23, S35, S68, S127

Clair, D., 790

Clark, C. A., S79

Clark, J., S186

Clark, M. M., S25

Clarke, B. B., 46, S179

Clavibacter michiganensis, on potato, niche adaptation, S134

Claviceps purpurea, materia medica, S143

Clément, C., 1060

Clement, P. A., S109

Clément-Mathieu, G., S83

Cleveland, T. E., 87, S16

Clifford, J., S25

Cline, E. T., S25, S190

Cloud, G., S185

Clover yellow vein virus, on bean, Bean common mosaic virus linkage, S64

Cobb, A. C., S30

Cobb, J. N., S25

Cochliobolus spp.

-C. heterostrophus, on maize: quantitative resistance, 221; resistance loci, recombinant inbred lines, 1067

-C. sativus, on barley, mapping resistance loci, 699

Cochran, A., S167, S185

Cociancich, S., 1081

Coffee

-leaf rust, biocontrol, S44

_rust, epidemic chronicle, S143 -wilt, production constraints, Africa, symposium, 663

Coffey, M. D., 920, S12, S25, S74, S133

Cohen, L., 447, 1404

Cohen, Y., 417

Coker, D. L., S91

Colburn, G. C., S25, S190, S191

Cole, H., S4

Coleman, C. E., S112

Coleosporium tussilaginis, on Senecio vulgaris, tolerance, 718

Colgrove, A. L., S84

Collado-Romero, M., 288, 485

Collard, B., S15

Collections

—bacterial, genomics research role, S133

- genomics and bioinformatics, S133

- herbaria, value in DNA age, S133

- microbial, Canada, conservation, S133

—of plant pathogens, history, genomics age, S133

Colletotrichum spp.: on apple, etiology clarification, 982; fungicide, assay, S189; on turfgrass and corn, evolutionary lineages, 46

$-C$. acutatum: on cherry and apple, bud infection, S110; on strawberry, inoculum source in California, $\mathrm{S} 43$

- C. cereale: morphological structures, cover photo, January; on turfgrass, fludioxonil sensitivity, S74

-C. coccodes: on potato, variability and vegetative compatibility groups, 1097 ; on velvetleaf, bioherbicide, metallothionein, 1116

-C. gloeosporioides: host range, Russian thistle, S190; hyperparasite, transformation with protein, S107; on Limonium spp., benomyl resistance, 542; on pepper, etiology, S46; on pitaya, first report, S89; on strawberry, sexual recombination, $\mathrm{S} 72$

-C. trifolii, new race in Ohio, S6

-C. truncatum, on soybean, glyphosate and hemp sesbania interaction, $\mathrm{S} 15$

Collins, D., S25, S156, S157

Collins, H. P., S97

Collins, K., S79

Collins, R. T., S177

Collmer, A., S68, S81

Collmer, C., S68

Comes, S., S34

Compost, Allium white rot suppressed by, 1009

Conant, G. C., S94

Condeso, T. E., S145

Conedera, M., 1337

Conn, V. M., S26, S37

Connell, J. H., S26, S166

Conner, K. N., S26

Conway, W. S., S51, S75

Cook, A. Z., S13, S14

Cook, D. R., S68

Cooke, D. E. L., S134

Cooksey, D. A., S47

Cools, H. J., S11

Coop, L., S93

Copes, W. E., S26, S186

Coplin, D. L., S45

Corcuff, R., S26

Córdoba-Sellés, M. C., 274

Coremiotrichum foliicola, on rain forest, Brazil, new species, $\mathrm{S} 12$

Corn (see also Maize)

-aflatoxin and fumonisin contamination, planting date effect, Arkansas, S2

—anthracnose, evolution and lineage, 46

-Aspergillus parasiticus, systemic infection, S123

-kernel infection, aflatoxin, 87

-Pythium seedling disease, mefenoxam and azoxystrobin sensitivity, S87

-residue, Fusarium head blight and deoxyvalenol concentration affected by, S85
- smut, male sterile hybrids, S20

-Stewart's disease, forecasting in Iowa, S33

-sweet: crown and node necrosis, yield in Oregon, S169; rust, yield loss, S182

Cornus spp. (see also Dogwood): leaf blight, Phytophthora sp., S187

$-C$. florida, powdery mildew, biocontrol with bacteria, $\mathrm{S} 81$

Correll, J. C., 982, S12, S115, S118

Corylus avellana, filbert blight, epidemic in Pacific Northwest, S95

Costa, H. S., S47

Costanzo, S., S26

Côté-Beaulieu, C., S27

Cotton (see also Gossypium longicalyx)

-Aspergillus flavus, soil factors and rotations in Texas, 599

- diseases, biocontrol with Trichoderma virens, mechanism, 17

-Fusarium wilt, root-knot nematode relations, 727

-ramulosis, epidemiology in field, S81

-root-rot, host response, S2

- soilborne pathogens, Indian mustard cover crop, S10

Cotty, P. J., 599, S38, S94

Couderchet, M., 1188

Coughlan, S., S31, S86

Counts, J. W., S103

Courtois, J., 1278

Coventry, E., 1009

Cover photo

- Angelonia flower break virus, symptoms, May

-Alternaria citri, on citrus, histidine auxotroph mutant, September

-Colletotrichum cereale, morphological structures, January

-Cronartium ribicola, on pine, spore germination, February

-ginseng, Cylindrocarpon root rot symptoms, November

-mango, malformed inflorescence, June

-Norway spruce, top dieback symptoms, December

- Monilinia fructicola, on nectarine, appressoria, October

-Nicotiana benthamiana, Potato virus $X$ and Citrus tristeza virus sequences, August

-Ophiosphaerella agrostis, on creeping bentgrass, pseudothecia, March

- orange, Citrus exocortis viroid and Hop stunt viroid infection, April

—radish, Xanthomonas campestris, lesions, July

Cowger, C., 860

Cowpea, viruses, mixed infections, symptomatology, S112

Cox, K. D., S187

Cox-Foster, D., S127

Cranberry, fairy ring:

- genetic diversity, S93

-yield effect, S88

Crasta, O., S161

Crataegus sp., fire blight, plasmid pEA29 lacking, 900

Craven, K. D., S27

Creasap, J. E., S177

Crescenzi, A., S34, S97

Creswell, T., S1

Crinipellis perniciosa, in cacao, resistance genetics, S111

Crisosto, C. H., S89

Cristofani, M., 1092

Croft, H., 137

Croizat, F., S99

Cromey, M. G., S27, S167

Cronartium ribicola

-on Metasequoia and Pinus spp., spore germination, cover photo, February

-on Pinus monticola: antifungal peptide gene, 164; resistance, DNA markers, 395 
- on Pinus strobus, epicuticular wax and resistance, 171

-on white pine, landscape factors, North America, S145

Crop rotations, potato, Rhizoctonia diseases, 68

Crouch, J. A., 46

Crous, P., S10, S43, S139

Crowe, F., S167

Cryphonectria parasitica, on chestnut:

-hypovirulence, 1337

-phosducin-like protein, G-protein signaling, S101

Cryptococcus fagisuga, on beech, spread in North America, S145

Csinos, A. S., S7, S19, S27, S84, S184, S187

Cubeta, M. A., S59

Cucumber

-Colletotrichum lagenarium, resistance, S50

- downy mildew, organic agriculture for management, S34

-Fusarium root and stem rot, suppression by bacteria from composts, $\mathrm{S} 15$

-Pythium aphanidermatum, endophytic actinomycetes, disease relation, $\mathrm{S} 33$

Cucumber mosaic virus

-on cowpea, transformation for resistance, silencing mechanism, S60

-on pepper, Pepper mottle virus mixed infection, 240

-resistance evaluation, single-chain antibodies, S45

Cucurbits

— bacterial wilt, trap crops for, S67

- downy mildew, fungicide programs, S74

-organic production, disease management strategy, S11

- potyvirus, whitefly-transmitted, Florida, S3

Cui, X., 408

Culbreath, A. K., S31, S41

Culture collections, agricultural security, letter to editor, 920

Cuppels, D. A., S48, S54

Curly top virus, on cucurbit, leafhopper transmission, S22, 1164

Curtobacterium flaccumfaciens, on bean, biofilms and vascular clogging, S46

Cycad leaf necrosis virus, on cycads, first badnavirus, $\mathrm{S} 70$

Cylindrocarpon spp.

-C. destructans, on ginseng, iron effect, 1179

- C. parasiticum, on peanut, inoculation technique, resistance screening, $\mathrm{S} 31$

Cynara cardunculus, Verticillium wilt, diversity in Spain, 288

Cyperus esculentus, Rhizoctonia solani, plastic mulch beds, S19

Dactylella oviparasitica, beet-cyst nematode suppressed by, 111, 855

Dactylellina candidum, nematode trapped by, alfalfa, 1388

Dagraca, J. V., S114

Daleo, G. R., S69, S88, S124

Dally, E. L., S190

Damann, K. E., 87

Damasceno, C. B., S27

D’Ambrosio, M., 689

Dambroski, H. R., S27

Damicone, J. P., S30

Damsteegt, V. D., 616

Dandekar, A. M., 819

Daniel, R., S28, S62

D'Arcy, C. J., S28, S32

Dart, N. L., S166

Databases for fungi, usefulness, S25

Datnoff, L. E., S28, S46

Daub, M. E., S48, S141, S158

Dauch, A. L., 1116

Daugrois, J.-H., 33, 1081
Davelos Baines, A. L., S101

Davenport, J., S10, S12, S173

Davey, J. F., S76, S177

David, A. J., 171

Davidson, J. K., S14

Davis, C. G., S61

Davis, E. L., S75, S120

Davis, K., S190

Davis, M., S45

Davis, R. E., S56, S111, S190, S191, S192

Davis, T. M., S118

Dawe, A., S101, S190

Dawson, W. O., S41

Deahl, K. L., S26, S105

Dean, R. A., S31, S86, S94

de Bruijn, F. J., 876

De Cock, A. W., S72

DeCory, T. R., S176

Defense signaling, fatty acid metabolism, S57

De Garcia, M. C., S99

de Goes, A., S188

DeJong, T. M., 608

De Jong, W., S74

De Kievit, T., S12, S106

De la Cerda, K., S28, S97

De La Fuente, L., 751

Delaney, R. H., S168

Del Ponte, E. M., 797, S33

del Río, C., 313

Del Rio, L., S46, S95

Dematheis, F., S91

Deng, W., S81

Deng, X., S23, S71

Deniel, F., S97

Denman, S., S28

Denny, T. P., S131

de Oliveira, A. C., 1092

Depuydt, S., S135

Derin, E., 560

Dernoeden, P. H., 248, S58

De Silva, A., S58, S89, S119

Desjardins, A. E., S28

Desjardins, Y., S42

de Souza, J. T., 61, S71

Detection

- exotic species, group decisions and priorities, S105

-forest and ornamental survey, statistical methodologies, S144

-invasive pathogens, early response, S144

- surveys, classical and molecular technology, S144

Devries, R. E., S185

Dewdney, M. M., S29, S177

De Wolf, E., S31, S85, S91, S145

Dhuicq, L., 1188

Dhulipala, M. R., S29, S57

Diaporthe phaseolorum, on soybean, in Iowa, S70

Dias, A. S., S29

Diaz, M., S10, S29

Diaz-Rivera, J. B., 1046

Dickerson, J., S161

Didier, A., S57

Didymella spp.

-D. bryoniae, on melon, recovery from debris, S186

-D. rabiei, on chickpea, weather in Pacific Northwest USA, S23

Dighe, N., S11

Diguistini, S., S29

Dileo, M. V., S30

Dillard, H. R., S30, S180, S182

Ding, S.-W., 819

Diplodia spp.: on conifer, species-specific PCR primers, S109; on Pinus resinosa, on trees, seeds, and seedlings, S3; on red and jack pine, collar rot, S110

-D. pinea, on Scots pine, shearing effect, S10

Di Rico, J., S99
Dirks, B., S160

Disease diagnosis

-CANARY B-cell sensor, S83

-DDIS, web-based distance system, S80

- genome-based resource, threatening pathogen, S17

-mobile laboratory, Nebraska, S121

-Phytophthora ramorum, TaqMan chemistry, 846

-PCR sensitivity, multiple displacement amplification, S105

Disease forecasting, epidemiological model, S76

Disease management, organic strategy, vegetable crops, $\mathrm{S} 11$

Dixon, P. M., S33

Dodd, S. L., S30

Doddapaneni, H., S68, S127

Doetkott, C., 1097

Dogwood (see also Cornus spp.)

-flowering, disease control, fungicides, S45

-powdery mildew, epiphytic bacteria for control, S187

-soilborne diseases, control, S85

Dolezal, A. L., S30

Dolezal, W., S19

Doll, D. A., 308, S167

Dombroski, A., S10

Domier, L., S11, S149

Dominiak, J. D., S30

Donahoo, R. S., S30, S39, S114

Donat, V., 900

Dong, H., 1052

Dong, W., S31

Dong, Y., S2

Donofrio, N., S31, S86

Doohan, F. M., 386, S16

Dorner, J. W., S153

Dorrance, A. E., 186, S174

Doublet, B., S84

Douhan, G. W., S28

Dovas, C. I., 622

Dow, J. M., S136

Driever, G., S26, S81

Droby, S., S110

Druffel, K., S89

Du, L., S128

Dubois, A., 356

Dubois, C., 356

Dufault, N. S., S31

Duffié, L. E., S105

Duffy, B., S92

Dufils, A., 890

Dufour, J., S31

Dugan, F. M., S167, S168

Dumenyo, K. C., S47

Dumroese, R. K., 1124, S111

Duncan, R. A., 608, S166

Duncan, R. W., S148

Dunkle, L. D., S139, S143

Dunning, F., S111

Dunoyer, A., S123

Duque, A. P., S177

Duque, M. C., S41

Duran Vila, N., 356

Durand, R., 1278

Durham, T., S31, S114

Durst, R. A., S176

du Toit, L. J., S89, S118, S168

Duttweiler, K., S31, S64

Duxbury, J. M., S182

Earle, M. L., S73

Easley, S. A., S167, S171

Eastburn, D. M., S28, S32

Edmunds, B. A., S32

Egan, D., 386, S16

Ehret, G. R., 709

Ehteshamul-Haque, S., S167

Eikemo, H., S183 
Eilam, T., S112

Eilenberg, J., S60

Ekramoddoullah, A. K. M., 164, 395

Elad, Y., 1195

Elaeis guineensis, Fusarium wilt, symposium, 660

El-Aref, H., S2

Eldredge, S. D., S32

Elena, P. V., S103

Elias, E. M., 885, S108

Elliott, M. L., S185

Ellis, M. A., S96

Ellis, M. L., S32

Ellwood, S. R., 1330

Elm, Dutch elm disease:

-biocontrol with Verticillium, S104

-resistance, S156

Elmer, W. H., S32, S177

El-Mohtar, C. A., S32

Elsinoe spp.

-E. ampelina, on grape, outbreak in Quebec S177

-E. fawcettii, on citrus, elsinochrome toxins, S186

El-Tarabily, K., S33

Emerging plant pathogens, Florida, sentinel state, S46

Endophytes

- actinomycetes: cereal root disease control, S37; system defense pathways, S26

- diversity, small and large spatial scales, S136

—on Douglas-fir and ponderosa pine, burn sites, S137

- foliar, biodiversity in conifers, S137

_in forest, ecological role, S136

- grass, woody plant comparison, S136

—urban forest challenge, California, S157

Engelbrecht, C. J., S138

Englander, L., S115

Engle, J. S., 1355, S33

Enis, J. N., S29, S57

Enterobacter cloacae, Pythium ultimum interaction, seed exudation, $\mathrm{S} 124$

Epichlö̈ spp., bioprotective alkaloid produced by, loline, S34

Epidemiology, geostatistics and GIS application, S144

Epiphyte, bacterial pathogens, quorum sensing signaling, S150

Epstein, L., S76

Erard, G. S., S16

Errata

—annual meeting 2005, S131

—vol. 96, no. 6 (suppl.), 2006, 804, 1046, 1164 , 1416

Eruca sativa, trap crop for fungi and nematodes, potato, S97

Erwinia spp.

-amylovora: on apple, cell osmolality, analysis, $\mathrm{S} 174$; on apple, epidemic, pruning effect, S182 on apple, grafting effect on resistance, S101; on apple and pear, bacteriophages, monitoring, S179; on apple and pear, resistance gene identification, genomics, S86; on apple and pear, temperature requirements, S29; on apple and pear, virulence component, thiamin biosynthesis, S75; autoinducer-2, S80; biocontrol, New York, S183; on Crataegus, plasmid pEA29 lacking, 900; gene upregulation, tissue colonization, S175; host and pathogen genetic response, S147; liposomes for detection, S176 MARYBLYT program, population estimates, S177; on pear, symptomless fruit, S171; virulence genes, deletion, S179

-E. carotovora: on potato, phytotoxins and resistance, S96; on wasabi, rhizome blackening, S98

-E. chrysanthemi, on pineapple, monoclonal antibody, S58

-E. tracheiphila, on cucurbit, specific primer, $\mathrm{S} 122$
Erysiphe spp.

-E. cichoracearum, on zinnia, silicon effect, S70

-E. pulchra, on flowering dogwood, epidemiology in Tennessee, S186

Eskalen, A., S33, S99, S168

Eskandari, F. M., S17, S191

Esker, P., S33, S81, S86, S98

Essenberg, M., S93

Eudes, F., S39

Euscelidius variegatus, vector for Flavescence dorée phytoplasma, specificity, 790

Eutypa lata, on grape:

—-species reassessment, 369

-virulence factors, S99

Evangelisti, A. M., S94

Evans, C. K., 567, S33

Evans, H. C., S138

Evans, R. G., S140

Evans, T. A., S103

Everett, B., 735

Everts, K., S103, S130, S192

Eyles, A., S34, S119

Fahed, S. C., S34

Fairbanks, D. J., S112

Fajardo, J., S34

Fakhoury, A. M., S8, S72

Falacy, J., S168, 1416

Falk, B.W., 819

Fanigliulo, A., S34

Fare, D. C., S147, S186

Farina, G., S140

Farmer, M., S80

Farr, D. F., S25, S133, S190

Farrar, J. J., S168

Farrell, R. E., S86

Farrokhi-Nejad, R., S27

Faske, T. R., S34

Faulkner, J. R., S34

Fauquet, C. M., S154

Fawley, M., S3

Fazio, G., S101

Feau, N., S15, S34, S35

Febres, V., S35

Feldmann, T., S10

Feldstein, P. A., S35

Feliciano, A. F., S43

Felts, D., S81

Feng, C., S115

Feng, J.-X., S136

Feng, Z., S23

Ferguson, B. J., S88

Fernandez, J., S35, S162

Fernández-Muñoz, R., 1263

Fernández-Pavía, S. P., S99

Fernando, D. G., S12

Fernando, D. W., S106

Fernando, M., S124

Ferrandino, F. J., S32, S177

Ferrer, A., 313

Fery, R. L., S114

Fessehaie, A., S35

Fetzer, J. L., S70

Feussner, I., S38

Fichtner, E. J., 212, S30, S35

Fidanza, M. A., S58

Fierro-Coronado, A., S103

Figuli, P. J., S24

Filgueira, J. J., S36

Filho, O. G., 1092

Finley, L., S51

Fischbeck, G., 436

Fischer, S., 386

Fisher, A. J., S25, S36

Fjellstrom, R., S54

Flanigan, H., S74

Fletcher, J., S19, S77

Flood, J., 660

Florea, S., S36
Flores-Cruz, Z., S36

Floyd, C. M., S9

Fontaine, F., 1060

Foo, E., S88

Food safety, tomato and pepper fruits, decontamination with dimethyl benzyl ammonium chloride, S116

Forage grasses, endophytic bacteria, plant growth promotion, S59

Forbes, G. A., 777

Forest

- ecosystem, Mississippi, hurricane effect, S157

- environmental challenge to urban trees, S158

- exotic pathogens and pests, Canadian response, S157

-urban: five threats, S158; New Orleans, Hurricane Katrina effect, S25; soil factors, S157; wood waste utilization, S158

Forest, M., S36

Forestry, urban, health management, S156

Forster, H., S26, S58, S166, S169

Forster, R. L., 876

Fortier, E., S178

Fory, P., S59

Fossdal, C. G., 1305

Foster, K. A., S181

Foster, M. J., S64

Fouhy, Y., S136

Foulkes, M. J., 680

Fouly, H. M., S36

Fraaije, B. A., S11

Fraile, A., 274

Franc, G. D., S140

Francis, I., S135

Franco, C., S26, S37, S80

Franco-Lara, L., S36

Frank, E. E., S37

Frank, K. L., S145

Franklin, R. B., S115

Frantz, J., S87

Frate, C., S85

Fraxinus sp., phytoplasma, optical technique for identification, S36

Frederick, R. D., 336, 616, S14, S104, S191

Freeman, S., 542

Freitas-Astúa, J., 1092

French-Monar, R. D., S185

Frey, J. E., S92

Frey, P., 1027, S34

Fricke, W., S174

Fromentin, J., S80

Fry, W. E., 1397, S18, S74, S177, S180, S186

Fuchs, M., S178

Fucikovsky, L., S37

Fucikovsky-Zak, L., S74, S94

Fujita, Y., 746

Fukuda, S. K., S14

Fulton, S. E., S148

Fumigation

- dimethyl disulfide, nematodes and fungi, S100

-methyl isothiocyanate, mulched soil beds, distribution, S184

Fungicides (general) (also see Fungicides, specific)

-biofungicides, EPA registration, $\mathrm{S} 16$

-biopesticides, IR-4 role in regulatory assistance, S16

-Botrytis, on grape, mode of action, S131

-Phytophthora infestans, field population, center of origin, 1397

-screening and efficacy testing, anti-biofilm products, $\mathrm{S} 73$

- spray heterogeneity, resistant pathogen regional spread, 549

- sterol demethylation inhibitor, resistance to Blumeriella jaapii, 709

Fungicides (specific) (also see Fungicides, general)

-aluminum, Phytophthora parasitica and Thielaviopsis basicola, 212

-benomyl, Colletotrichum gloeosporioides on 
Limonium spp., resistance, 542

-benzothiadiazole, petunia, potato, and tomato, molecular response, $\mathrm{S} 177$

- copper, technology, new from DuPont, S123

-mandipropamid: late blight and downy mildew of tomato, potato, and cucurbit, S185; oomycete control, properties, S51

-Triflumizole, tree nut, fruit, vegetable, and vine crop control, S34

Funnell, D. L., S37

Fusarium spp.: banana vs. carnation leaves for identification, S83; on cassava, complex in West Africa, symposium, 673; conifer nursery, molecular characterization of species, S111; on corn stubble, Connecticut, S32; on ginseng, detection methods, S41; on ginseng, rusty root S170; grassland soils in New Zealand, S27; on mango, malformation in Mexico, S99; mango, malformation, symposium, 667; tropical perennial crops, symposium, 648; on wheat and barley, head blight, biofilm and fungicides, S46

-F. avenaceum, on cabbage, head rot in New York, S30

-F. circinatum, on pine, symposium, 657

-F. culmorum: on rye, variability in Russia, S102; on wheat, PCR assay, tri5 gene, S92

$-F$. graminearum: on barley, fungus and lesion distribution in florets, 567; on barley, protein analysis, S39; population shifts, Upper Midwest, S37; on wheat, blight and deoxynivalenol, meta-analysis, 951; on wheat, head blight resistance in recombinant inbred population, 534; on wheat and barley, inoculum dynamics in South Dakota, S88

$-F$. moniliforme, phylogenetics, old and new clades, S55

-F. oxysporum: beet-cyst nematode suppressed by, 855 ; bikaverin, activity against Phytophthora infestans, S109; on birdsfoot trefoil, wilt in New York and Vermont, S125; in conifer nursery, $F$. commune comparison, 1124; on cotton, relation to root-knot nematode, 727 ; on lettuce, PCR-based method, two-step, S75; on lettuce, seedborne transmission, S132; on lettuce, sequence-specific amplified polymorphism, S91; on oil palm, symposium, 660; on tomato, race 2 , resistance gene, $\mathrm{S} 32$; on watermelon, race 3 , new, $\mathrm{S} 130$

- F. pseudograminearum, on cereal residue, displacement by antagonists, S107

-F. solani: on blueberry, root rot, S124; on cucurbits, race 1, control, S76; on soybean, cys nematode interaction, factorial experiments, 1409; on soybean, Heterodera glycines interaction, 763; on soybean, mapping-resistant loci, S61

-F. verticillioides: on corn, ear dissemination, S128; fumonisin biosynthesis, protein phosphatase, S24; on maize, sphinganine accumulation, S93; polyketide synthase genes, S95

-F. virguliforme, on soybean, molecular study, S72

-F. xylarioides, on coffee, production constraints, Africa, symposium, 663

Fusicladosporium effusum, on pecan, nickel effect, S97

Fusicoccum sp., on pistachio, prediction of blight by Bayesian methods, 1142

Gabriel, D. W., S154

Gadoury, D. M., S6, S19, S39, S86, S178, S183

Gaeumannomyces graminis

-on turfgrass: genetic variation, S36; melanin role, GUS transformants, S36

-on wheat: disease-induced root growth, analysis, 510; Mn oxidation, multicopper oxidase, 130

Gafni, A., S92

Gagnevin, L., 1345
Gahegan, M., 920

Galagan, J. E., S137

Gale, L. R., S37

Gallegos, L. L., S33, S99

Gallian, J. J., S111

Galloway, H., S168

Gallup, C. A., S37, S185

Galvani, C. D., S180

Gambino, G., 1214

Gamez-Jimenez, C., S5, S38

Ganske, D. D., S92

Gao, X., 1409, S38, S79

Garavito, A., S18

Garay Serrano, E., 1397

Garbelotto, M., 846, S69, S74, S147

Garber, N. P., S38

García, A., 313

Garcia, C., S59

García-Arenal, F., 274

García-Cano, E., 1263

García-Jiménez, J., 288

Garcia-Pedrajas, M. D., S38, S40, S82

Gardner, J. F., 630

Garibaldi, A., S91

Garita, L., S81, S162

Garita-Cambronero, J., S81, S163

Garner, D., S89

Garnica, D., S38, S113

Garnsey, S., S77

Garrelly, L., S97

Garrett, K. A., S37, S39

Garrison, M. C., S108

Garza, A., S39, S101

Garzón, C. D., S178

Gasic, K., S86

Gavilanes-Ruíz, M., S93

Gay, D. A., S173

Geary, B. D., S25, S112

Geary, B. G., S20

Geddes, J. M., S39

Gee, C. T., S39, S178

Geider, K., S80

Geiser, D. M., 920, S12, S55, S131

Gelerntner, W., S155

Genes

-aflatoxin cluster, recombination and evolution, S138

- cluster, mutualistic grass-endophytes, S137

-clustering and: exchange, S137; genome evolution, fungi, S137

-fungal pathogenesis, duplication, S94

Gent, D. H., S39

Gera, A., 460

Geranium

-Botrytis blight, resistance induced by Trichoderma and Rhizoctonia, S87

— soil pathogens, leaf temperature relation, S87

Gérard, P. R., 1027

Gergerich, R., S60, S112, S116

German, T. L., S122

German-Retana, S., S84, S132

Gerson, U., S92

Gessler, C., 501

Gevens, A. J., S39, S173

Ghabrial, S. A., 326

Ghimire, S. R., S40

Ghoshroy, S., S140

Giammaria, S. L., S185

Gibberella zeae

— air population, genetics, 1021

- ascospores genetically modified out, inoculum field release, $\mathrm{S} 28$

-atmospheric population, genetics, S104

- triazole sensitivity, S62

-on wheat: propagule abundance, modeling, S91; propagule number and deoxynivalenol relation, S110

Gibson, D. M., S55

Gichuru, V. G., S40
Giesler, L. J., S121, S130, S185

Gilbertson, R. L., 1204, S45, S79, S130, S132, S148, 1164

Gilchrist, D., S160

Gildow, F. E., 828, S127

Giles, C., S82

Gillen, A. M., S111

Gillett, J. L., S40

Gillett, J. M., S104

Gilligan, C. A., 510, 549

Gillman, J. H., 171

Gilrein, D., S49

Gimenez, M., S19

Giménez-Jaime, A., 288

Ginseng (see also Panax quinquefolius)

-Alternaria panax, environment effect, S48

-Fusarium equiseti, rusty root symptoms, S41

- Cylindrocarpon root rot, due to iron, November cover

Giosuè, S., 155

Girard, J.-C., 33

Giraud, T., 280

Girish, A. G., S83

Giroux, G., S10

Gitaitis, R. D., S64, S84, S187

Glassbrook, N., S30, S50

Glawe, D., S168

Gleason, M., S10, S29, S31, S64, S65, S67, S81, $\mathrm{S} 82, \mathrm{~S} 122, \mathrm{~S} 126$

Glenn, A. E., S131

Gliocladium catenulatum, on cucumber, biocontrol for root and stem rot, S21

Globodera spp.

- G. pallida, on potato, genomic analysis, S149

-G. rostochiensis: chorismate mutase gene, mechanism, S71; on potato, peptides in glands, S70

Glover, T. J., S14, S64

Goates, B. J., 962, S132

Gobena, D., S51

Godon, J., S97

Godoy, C. V., 797, S81, S163

Godoy-Lutz, G., S40

Goetz, J. R., III, S137

Goh, J., S24

Gold, S. E., S38, S40, S82, S112

Gomez, M., S164

Gonzalez, C., S41

González, E., 982

González Altamiranda, E., S69

Gonzalez-Hernandez, J. L., 885

Goodman, M. M., 1067

Goodstein, D. M., S160

Goodwin, S. B., S3, S139

Göpfert, J. C., S47

Gorbet, D. W., S41

Gordillo, A., S113

Gordon, S. G., 593, S174

Gordon, T. R., 657, S157

Gore, R., S12, S173

Gorris, M. T., 320

Gosme, M., S41

Gossypium longicalyx (see also Cotton): reniform nematode, resistance transfer, S11

Goswami, R. S., S41

Gottschalk, K. W., S8

Gottwald, T., S13, S14, S52, S144

Gourlie, J. A., S167, S171

Govrin, E. M., 299

Gowda, M., S118

Gowda, S., S41, S117

Goyeau, H., 264, S42

Grabau, E. A., S91

Grabowski, M., S62

Graham, M. Y., S150

Graham, T. L., S150

Grando, S., 1214, S2

Grape

—Armillaria root rot, biocontrol, S10 
—bacterial leaf scorch, xylem pathway, S21

-black foot, biocontrol with Glomus intraradices, $\mathrm{S} 170$

-Botryosphaeria canker, Mexico, S117

- canker, pathogens in California, S117

-Cladosporium rot, Chile, S16

-crown gall, biocontrol mechanism, S177

-disease control, sulfur and copper, S104

-diseases, bordeaux mixture, and history, S143

- downy mildew: Alternaria alternata interaction, 689; controlled by Inula viscosa extracts, 417; fungicide resistance, QoI, S190; latent period, humidity and cultivars, S19

- downy and powdery mildews, resistance, S18

- esca: inoculum sources, S99; photosynthesis alteration, 1060

-Eutypa dieback, species concept, reassessment, 369

-Eutypa lata and E. vitis, distinguishing with PCR, S174

- germplasm collection, genetic diversity and resistance, $\mathrm{S} 176$

- gray mold and downy mildew, chitosan oligomers and copper sulfate, 1188

—ontogenic resistance, proteomics techniques, S39

-Phomopsis and Botrytis shoot blight, control, California, S65

-Pierce's disease, winter temperature, S5

-Plasmopara viticola, population structure in Greek island, 501

- powdery mildew: detection with PCR primers, S168; fungicides, risk assessment model, S168; hypersensitivity and resistance, S17; mineral oil formulations, S65; shading effect on severity, S6

- soilborne bacterial community, factor analysis, S90

- summer rots, cane pruning, North Carolina, S5

-Togninia spp., new species in California, S33

- viruses, multiple detection by RT-PCR, 1223

Grapevine berry inner necrosis virus, longdistance movement, interference, 378

Grapevine leafroll-associated virus, mixed infections, Washington, S83

Grassland, epidemiology, tallgrass prairie, S39

Grau, B. L., S42

Grau, C. R., S174

Gravel, V., S7

Gray, F. A., S168

Gray, S. M., 828, S8, S127, S152, S181

Greene, M. D., S42

Greene, S. E., S44

Greenhouse crops, abiotic and biotic stressors, color infrared imagery, S186

Grégoire, C., S80

Gregoire, G., S42

Gregory, N. F., S103

Gregos, J., S58

Gremillion, S. K., S158

Gremmeniella abietina, on Norway spruce, Phomopsis association, detection, 1305

Grenier, E., S149

Greslebin, A., S42

Greve, C., S136

Greve, L., S99, S100

Grewal, P. S., S11

Gribaudo, I., 1214

Griffin, M. R., S42

Griffin, R. L., 975

Griffin, T. S., S64

Griffiths, H. M., S43

Grimaldi, P., S95

Grisham, M. P., S43

Groenewald, J. Z., S43, S139

Groenewald, M., S43, S139

Grondin, G., S36

Grondin, J., S15

Grondona, I., S164
Gross, D. C., S148

Grossman, R. B., S34

Groth, D. E., S43

Grove, G. G., S169, S170

Grove, G. L., S18, S168

Grover, V., S77

Groves, R., S22

Grube, R. C., 1380, S124

Gruber, B. R., S43

Grunden, E., S174

Grünwald, N. J., 920, 1134, 1397, S43, S75, S147, S168

Grybauskas, A., S103

Guan, D., S42

Guaragna, M., S56

Gubler, D., S43

Gubler, W. D., 369, S33, S99, S117, S166, S168, S170, S172

Gubrij, K., S55

Gudmestad, N. C., 1097, S141

Guerra, N., S171

Guerra-Moreno, A. S., S163

Guerrero, J. C., S117

Guest, D. I., S28, S62, S138, S139

Guevara, M. G., S88

Guevara Lugo, J., S117

Guével, M., S27, S178

Gugino, B. K., S44, S176, S178

Guilhabert, M. R., S136

Gullino, M., S91

Guo, B., S71

Guo, X., 1052

Gutierrez, L., S109

Gutierrez, S., S165

Gutierrez Chapin, L., S100

Gwinn, K. D., S25, S44, S73

Gypsophila paniculata, deformation disease, nutrition effect, 771

Haber, S., S44

Hacisalihoglu, G., S44

Haddad, F., S44

Hagan, A. K., S19, S45

Hagen, C., S45

Halbrendt, J. M., S115

Halbrendt, N. O., S115

Halgren, A., S116

Halik, S., S178

Halkett, F., S42

Hallett, S. G., 308, S107

Ham, J., S45

Hamada, W., S55

Hamasaki, R. T., S14

Hameed, K. M., S46

Hamelin, R., S15, S34, S35, S74

Hammami, W., S80

Hammerschmidt, R., S32, S47, S49, S50, S150

Hammond, J., 460, S45, S73

Hammond, R., S26, S45, S56, S96, S111, S190, S191

Han, S., S24, S45, S106

Han, Y., S66

Handelsman, J., S158

Hang, L., S66

Hansen, E., S42, S90, S96, S97, S170

Hanson, L. E., S141

Hao, G., S177, S178, S180

Hao, J., S45

Haque, M. S., 96

Harding, M. W., S46, S73

Hardy, G., S33

Harikrishnan, R., S46, S60

Harlin, K. S., S9, S173

Harling, R., 408

Harmon, C. L., S46

Harmon, G. F., 190

Harmon, P. F., S46, S101

Harness, A., 460

Harp, T., S46, S185
Harri, J., S33

Harrington, T. C., S138

Harris, S., S128

Harrison, S. A., S14

Harsh, S46

Hartman, G. L., 1409, S8, S31, S38, S48, S61, S68, S82, S88, S91, S109

Hartman, J. R., S10

Hartung, J., S51, S67, S81, S162, S163, S164

Hase, S., 517, 908

Hassan, M., S2

Hausbeck, M. K., S39, S48, S103, S104, S173

Havens, W. M., 326

Hawatema, M. S., S46

Hay, F. S., S92

Hayden, K., 846

Hayden, M. J., 96

Hayes, P. M., 699

Hayes, R. J., 1380, S117, S124

Hayes, S., 137

Hayslett, M., S47, S57

He, S., S77, S151, S180

He, Y.-Q., S136

He, Z. H., 784

Heatherly, L., S78

Hebbar, K. P., 61

Hebbar, P. K., S139

Hed, B., S179

Hede, A., S169

Heidel, T., S87

Heilmann, L. J., 1097

Heiniger, U., 1337

Hekimhan, H., S169

Heller-Dohmen, M., S47

Hellier, B. C., S167

Helliwell, E., S174

Hellsten, U., S160

Helminthosporium victoriae, virus infection, phenotype, binding protein, 326

Helms, T. C., S173

Henning, A. A., 1000

Henning, S., S36

Henriquez, M., S72

Herder, K., S47

Hermansen, A., S86

Hermosa, M. R., S165

Herms, D., S34, S61, S157

Hernandez, E., S96

Hernandez-Bello, M. A., 1148

Hernandez-Martinez, R., S47

Herrera, C., S48, S119, S179, S180

Herrero, S., S48, S141

Hershman, D. E., S185

Hert, A. P., S48

Hesse, C., S96

Hesterberg, D. L., 212

Heterodera spp., secreted peptides, analysis, S120

-H. annosum, on fir, stump removal effect, S166

-H. avenae: distribution in Turkey and Syria, S166; on wheat, Turkey, S169; on wheat, yield effect, Oregon, S167

- H. glycines: nanotechnology, genome, S149; on soybean, bionomics and management, Michigan, S173; on soybean, Fusarium solani interaction, 763; on soybean, Fusarium solani interaction, factorial experiments, 1409; on soybean, new hosts and cultivars, adaptability, S84; virulence, genetic analysis, S11

-H. schachtii, on sugar beet: Dactylella oviparasitica effect on, 111; suppression by fungi, field plots, 855

Heu, S. G., 867, S66

Hickman, L. L., S184

Hidayat, S. H., 517

Hietala, A. M., 1305

Higashi, K., 967

Higham, J. M., S48

Highland, H. B., S48

High Plains virus, Kansas, S106 
Hilf, M., S41, S77

Hill, C. B., S48, S88

Hill, J. H., S155

Hill, J. P., S13

Hill, S. N., S48

Hillman, B. I., 46, S143

Hinton, D. M., S7

Ho, J., S116

Hoagland, R. E., S15, S121

Hobbs, H. A., S48

Hoch, H. C., S113, S180

Hodges, A., S49, S80

Hoenisch, R., S49

Höfte, M., S146

Hogenhout, S. A., S122, S135

Hoheisel, G.-A., 1134

Hoitink, H. A. J., 186, S4

Hoke, S. M. T., 1243

Holb, I. J., S49

Holbrook, C. C., S31

Holguín-Peña, R. J., S95

Holland, J. B., 1067

Hollosy, S. I., S49, S50

Hollowell, J. E., S50, S108

Holm, R. E., S16

Holmes, G. J., S32

Holmes, R. A., S50

Holsters, M., S135

Holtschulte, B., S141

Holzinger, J., S100

Homma, Y., 1000

Honeycutt, C. W., 68, S64

Hong, C., S40, S51

Hong, J., S51

Hong, L., S161

Hong, S., S61

Hong, Y., S50, S51, S52

Hood, I. A., 630, S30

Hop, powdery mildew, in Pacific Northwest, fluctuation, S169

Hopcroft, D., S181

Hopkins, D., S136

Hopp, H. E., 1175

Horibe, M., S79

Horn, B. W., S138

Horseradish, root discoloration, set treatment, S7

Horst, L., S4

Hou, S., S130

Houot, V., S80

House, E. S., S51

Howard, R. J., S46, S73

Howd, D. S., S163

Howell, B., S68

Howell, C. R., 178

Hsu, C., S51

Hsu, H.-T., 1296, S21, S45, S73

Hsuan Yuan, C.-H., 1296

Hu, G., S53

Hu, J. S., S14, S77, S106

Huang, B., S42

Huang, C.-W., 1296

Huang, H., S81

Huang, Q., S129

Hubbes, M., S156

Huber, D. M., 130

Huberli, D., S147

Hudler, G., S83, S121, S158, S159, S181

Hudson, M. E., S149

Huebner, H. J., S152

Huettel, R., S87

Huggenberger, F., S51

Hughes, G.. (Scotland), S76

Hughes, G. R. (Canada), 885

Hughes, J., S112

Hughes, K. J. D., 975, S74

Hulbert, S. H., S37

Humann, J., 105

Humeau, L., 1345

Hunger, R. M., 496, S24
Hunt, R. S., 395

Hurtado-Gonzales, O. P., S30, S51

Huryn, K. L., S28

Hussaini, S. R., S34

Husson, C., 1027

Huynh Thanh, T., S10, S52

Hwang, J., S52, S120, S185

Hyakumachi, M., S79

Hypersensitivity

- Botrytis cinerea on Arabidopsis, elicitor induction, 299

— signal cascade, S149

Hyun, J., S52, S56, S66

Ibragimov, T. Z., S102

Ichinose, Y., S74

Idowu, O. J., S44

Ignatov, A., S52

Iizumi, H., 1000

Ikeda, H., 967

Ikegami, M., 517

Imazaki, I., 1000

Impatiens necrotic spot virus, population structure in five continents, $\mathrm{S} 1$

Impullitti, A., S52

Inagaki, Y., S74

Inglese, S. J., 718

Inguagiato, J. C., S179

Inguil Rojas, E. H., S84

Inman, A. J., 975

Innes, L., S15

Integrated pest management, Florida, statewide program, S40

International Plant Diagnostic Network, multinational collaboration, development, S79

Inula viscosa, grape downy mildew controlled by extracts from, 417

Ioannidis, P. M., S142

IR-4, fungicide registration update, S114

Irey, M. S., S52

Iriarte, F. B., S53

Iriki, N., S84

Iris yellow spot virus

—new host and location, S187

-on onion: detection in bulb and seed crops, S89; Peru strains, S84

Irish, B. M., S12, S115

Irwin, J., S171

Isard, S. A., S31

Ishiguro, K., 425

Ishihara, T., 908

Ishimaru, C. A., S134

Isleib, T. G., S108

Isogai, M., 378, S112, S126

Isshiki, A., 934

Ito, M., S84

Ivey, M., S4

Ivors, K. L., 846, 920, S13, S42, S147

Iwanami, T., S155

Iwata, M., 908

Izzo, A. D., S53

Jabaji-Hare, S. H., 1116

Jablonski, R., S109

Jackson, C., S123

Jackson, E. W., 962, S14, S53

Jackson, T. A., 1409

Jacobi, V., S6, S15, S31

Jacobi, W. R., S62

Jacobs, J. L., S32

Jacobsen, B. J., S142

Jacobus, C. A., S53

Jacquot, E., S99

Jaffee, B. A., 1388

Jaime-Garcia, R., 599

Jakobek, J. L., S138

Jama, A. N., S117

Jambunathan, N., S76

James, D., 137, S154
James, R. L., 1124, S111

Jan, F., S21, S22, S130

Jang, K., S109

Janisiewicz, W. J., S51, S53, S75

Jansen, R., S54

Jarugula, S., S83

Jarvis-Metcalfe, A., S54

Jayaraj, J., S54

Jayaraman, J., S119

Jean, K. K., 867

Jeandet, P., 1188

Jeffers, S. F., S146

Jeffers, S. N., S19, S52, S96, S120, S146

Jellen, E. N., S112

Jellison, J., S182

Jeong, M., S106

Jeung, J. U., 867

Ji, M., S24

Ji, P., S44, S51, S54

Jia, M., S54, S55, S118

Jia, Q., 1052

Jia, Y., S54, S55, S118

Jijakli, M. H., 80

Jimenez, J. I., S78

Jiménez-Díaz, R. M., 288, 485

Jimenez-Gasco, M. M., S55, S118, S131

Jimenez-Hidalgo, I., S168

Jin, Y., S55, S110

Jines, M. P., 1067

Jmour, W., S55

Jo, Y., S55, S62

Jobin, T., S179

Jochum, C., S128

Johnson, A., S158

Johnson, B. J., S2

Johnson, D. A., 1097

Johnson, E., S55, S135

Johnson, G. R., S158

Johnson, J. J., S173

Johnson, J. L., S9

Johnson, K. B., S171

Johnson, K. L., S55

Johnson, P., 926

Johnson, R. M., S43

Johnston, W. J., S82

Jolly, P. E., S152

Joly, D. L., S34, S35

Jomantiene, R., S56, S190, S191

Jones, A. L., 709, S63

Jones, C., S180

Jones, D., S56, S94, S131

Jones, J., S48, S51, S53, S54, S98, S133, S149, S158

Jones, M. W., S56

Jones, R. A., S71

Jones, R. W., S26

Jonson, G., S56

Jordá, C., 274

Jordan, R., S56

Jordan, S. A., S57, S104, S174

Joshi, M., S57, S135

Joshi, R., 145, S100

Josselin, M., S57

Jossey, S., S57

Jost, P. H., S186, S188

Jun, J., S24

Jung, G., 926, S21, S55, S62

Jung, J., S89

Jung, K., S52, S56

Juzwik, J., S47, S57, S158

Ka, S., S109

Kabashima, J., S147

Kachroo, A., S20, S57

Kachroo, P., S20, S57

Kadooka, C. Y., S116

Kaewnum, S., 1230, S179

Kahlon, A. S., S163

Kaimoyo, E., S150 
Kakutani, K., 967

Kamenidou, S., S57

Kaminski, J. E., 248, S58

Kamoun, S., S4

Kamphuis, L. G., 1330

Kanaan-Atallah, Z., S58

Kane, R. T., S36

Kaneshiro, W. S., S58

Kanetis, L., S58, S131, S169

Kang, H., S58, S66, S89

Kang, L., S120

Kang, M. H., S86

Kang, S., 920, S12, S90

Kankanala, P., 346

Kaplan, A., S169

Karaoglanidis, G., S142

Karimi Jashni, M., S96

Karp, M. A., S59

Kasson, M. T., S59

Katan, T., 1195

Katawczik, M. L., S59

Katis, N. I., 622

Kato, M., 1000

Katoh, H., 934

Kaur, S., S46

Kav, N., S127

Kawagishi, H., S79

Kaye, A. C., S59

Kazemi, H., S96

Keinath, A. P., S85, S121, S186, S187

Keiper, F. J., 96

Kelemu, S., S59

Keller, K. E., S116

Keller, N. P., S106

Kelly, B. A., S109

Kemerait, R. C., S186, S188

Kennedy, G. G., S59

Kenney, M. J., S60

Kerem, Z., S92

Kerlan, C., S99

Kerns, J. P., S60

Kerrigan, J., S145

Khalil, A., S86

Khan, B., S60

Khan, J., S60, S140, S142

Khan, M. F., S60, S140, S142

Khan, M. R., 386

Khan, V. A., S110

Khang, C.-H., 920

Kianian, S. F., 885, S108

Kichler, J., S186

Kiewnick, S., S60, S156

Kim, B., S24, S45

Kim, E., S61

Kim, H., S89, S90, S106, S109

Kim, H. Y., 425

Kim, J., S24, S60, S66, S106, S109, S128

Kim, J. D., S52, S56, S86

Kim, J. W., S60

Kim, M., S52, S56, S89, S90

Kim, M.-S., 1124, S111

Kim, S., S24, S61, S66, S90, S106

Kim, S. H., 920

Kim, T., S66

Kim, W.-S., S179

Kim, Y., S24, S60, S61, S65, S66, S106

Kimberley, M. O., 630

Kinrade, S. D., S27

Kirk, S., S28

Kirkpatrick, B. C., 608, S68, S78, S100, S119, S136

Kiselyova, M. I., S63

Kistler, H., S37

Kitajima, A., 378

Kitner, M., S43

Klaine, S. L., S147

Klass, C., S49

Klassen, W., S61, S80

Kleczewski, N. M., S61, S157
Kleczkowski, A., 510

Kleinhenz, M. D., S11

Kleist, E., S54

Klessig, D., S20, S150

Kline, W. L., S125

Klingeman, W. E., S42

Klix, M. B., S62

Klopfenstein, N. B., 1124, S111

Kluepfel, D. A., S75, S90, S111, S167

Klutsch, J. G., S62

Kniskern, J., S149

Knudsen, G. R., 1108

Ko, S., S90

Kobayashi, D. K., S154

Kobayashi, D. Y., S154

Kobayashi, K., 425

Kobayashi, T., 425

Kobori, T., S126

Koch, D. W., S168

Koch, P., S62

Koebnik, R., S135

Kohalmi, S. E., S107

Kohout, M. J., S170

Koike, S. T., S114

Koizumi, S., 1000

Köller, W. D., S90

Kolmer, J., S62, S87

Kolomiets, M., S38, S79

Kolomiets, T. M., S62

Kon, T., 517

Konam, J., S62

Kong, P., S51

Korban, S. S., S86

Korolev, N., 1195

Korth, K. L., S81

Koski, T., S13

Kousik, C. S., S63, S186

Koutsoudis, M., S48, S119, S179, S180

Kovalenko, E. D., S63, S102

Krakowsky, M. D., 1067

Kraus, J., S63, S79

Krause, C., S70, S87, S147

Krause-Sakate, R., S132

Krohn, A. L., S124

Krueger, W. H., S17

Kruger, E. L., S43

Krupa, S. V., S173

Kubisiak, T., S74

Kubota, M., S79

Kuhn, D. N., S139

Kuhn, P. J., S51

Kuldau, G. A., S55, S63, S131

Kumar, D., S150

Kuninaga, S., S40

Kunkel, D. L., S16, S114

Kuo, Y.-W., 1296

Kurkova, N. N., S130

Kurle, J. E., S9, S63

Kuroki, M., S84

Kurtenbach, E., S53

Kusakari, S., 967

Kushalappa, A., S181

Kushnir, L., S92

Kwon, M., S6

Kyhl, J. F., S57

Labavitch, J., S99, S100, S136

Labbé, C., S83

Labonne, G., 890

Labonte, D. R., S79

Labyrinthula sp., on turfgrass, salt and water stress effect, S170

- L. terrestris, genetic diversity, on turfgrass, S27

Laguna, I. G., S19

Lakshman, D., S63

Lakso, A. N., S6

Lalancette, N., S17, S181

Lambert, J., S90

Lambert, K. N., S11, S91, S149
Lamondia, J. A., S180

Lamour, K. H., S30, S39, S51, S114, S134, S147, S173

Landa, B. B., 751, S170

Lane, C. R., 975

Lang, E., S153

Lang, J. M., S64

Lange, H. W., S64, S176, S180

Langston, D. B., S64, S84

Languasco, L., 155

Lannou, C., 264, S42

LaPaglia, C., 1108

Lapchyk, L., S57

Lapidot, M., 447, 1404

Larkin, R. P., 68, S64

Larsen, R., S64, S125, S169, S171

Lartey, R. T., S140

Lascano, C., S59

Latham, L. J., S71

Latinovic, J., S64

Latorre, B. A., S16, S65

Lauckner, B., S61

Lauffer, S. M., S158

Lauritzen, A. J., S60

Lauzier, A., S36

Lavigne, C., 280

Lavkovits, I., 771

Lawrence, J., S137

Layne, D. R., S187

Lazarovits, G., S120

Lazebnih, N. J., S63

Leach, J., S17, S37, S70, S121, S136

Lea-Cox, J. D., S40

Leal-Lara, H., S20

Leavitt, G. M., S65, S117, S172

Le Corronc, F., S65

Leder, E. H., S86

Lee, B., S24, S58, S66, S89

Lee, C., S61, S90

Lee, D., S58, S66, S71, S86

Lee, E., S89

Lee, F. N., S66

Lee, H., S65

Lee, I.-M., S190, S191, S192

Lee, J., S60, S66, S106

Lee, K., S52, S57, S66, S89, S90

Lee, M.-H., 1072, 1372, S66

Lee, R. C. M., S166, S167

Lee, R. F., S35, S163

Lee, S., S61, S66, S90, S109

Lee, T., S65, S76

Lee, Y., S24, S45, S61, S90, S106, S109, S128

Lee, Y.-H., 920

Lee, Y.-K., S61

Lee, Y.-W., 920

Lefeuvre, P., S99

Le Floch, G., S65

Le Gac, M., 280

Le Gall, O., S84, S132

Legard, D. E., S72

Legge, B., S39

Lehman, B. L., S104, S115

Lehman, S., S179

Leifsonia $x y l i$, albicidin, up regulation, detoxification pump, S9

Leiner, R. H., S124

Leite, B., S67

Lemtiri-Chlieh, F., S149

Leng, Q., S149

Lenssen, A. W., S140

Lenzi, R., 560

Leonard, R. T., S28

Leppla, N. C., S40, S114, S187

Leptosphaerulina trifolii, on Medicago spp., transformation, S29

Lertsuchatavanich, U., S67

Lesemann, D. E., 437, 622

Leslie, J. F., 673, 1021, S104 
Lesser, K. M., S17

Letter to the Editor, culture collections, agricultural security, 920

Lettuce

—Big vein, nursery practices in Australia, S71

-drop: fungicides, California, S116; incidence and population, Sclerotinia spp., 1322

-Fusarium wilt, soil flooding and solarization, S169

-Verticillium wilt: postharvest quality, S117; race-specific interactions, 1380

Lettuce necrotic stunt, virus biology and genetics, $\mathrm{S} 124$

Leveillula taurica, on onion, Washington, history, S168

Leverentz, B., S51

Levesque, A., S17

Lévesque, C. A., 637, S41, S133, S134, S146

Levi, A., S188

Levine, A., 299

Levy, D., 1404

Levy, L., S67

Lewandowski, S. M., 567, S63

Lewellen, R. T., S69

Lewis, G., S67, S122

Lewis, J. A., S35

Lewis Ivey, M. L., S11, S46

Leyva-López, N., S5, S21, S38, S67, S77, S103

Lherminier, J., S80

Li, H., S67

Li, R., S68

Li, S., S68, S109, S128

Li, W., S67, S81, S162, S164

Li, X., 797, S68, S69

Li, Y., S180, S186

Liang, S. S., 784

Liao, H.-L., S186

Liefting, L. W., 838, S68

Lilley, C., S149

Lim, H., S109

Lim, S., S58, S66

Lima, W., S136

Lime, citrus canker, chemical control, Thailand, S67

Limonium spp., anthracnose, benomyl resistance, 542

Lin, H., S68, S127

Lin, M., S21

Lin, N.-C., S151

Linde, C. C., 941, 1214, S2, S128

Lindeberg, M., S68

Linderman, R. G., S43, S75

Ling, K., S69

Linzer, R. E., S69

Liobell, A., S164, S165

Lipps, P. E., 593, 951, 1355, S91

Lisianthus necrosis virus, new host, S21

Listeria monocytogenes

- on honeydew melon, biocontrol, S51

-model organism, molecular evolution, S135

Little, C. R., S101, S186

Littlefield, J., S191

Liu, B., S98

Liu, F. (China), 1052

Liu, F.-L. (Taiwan), 1296

Liu, H. (Nanjing, China), 1052

Liu, H. (Calif.), S69

Liu, H. (Ga.), S131

Liu, H. Y. (Beijing, China), 784

Liu, J. (Pa.), S76

Liu, J.-J. (Canada), 164, 395

Liu, Q., S23

Liu, W., S69

Liu, Y., S69, S168

Liu, Z., S68, S148

Llop, P., 900

Lo, C., S69

Lobato, M. C., S69

Locke, J., S70, S87
Lockhart, B., S70, S72

Loewen, P. C., S12

Loguercio, L. L., 61

Lolium rigidum, gummy disease and toxicity, genetic diversity, 1270

López, M. M., 313, 900

López, R., 1204

Lorbeer, J. W., S106, S182

Loria, R., S37, S42, S55, S57, S80, S135

Lorieuz, M., S18

Lorito, M., 181, S164

Lough, T., S181

Louie, R., S56

Louws, F. J., 876, S98, S135

Lowe, C., S93

Lozano, I., S18

Lozoya-Saldaña, H., 1397

Lu, H., S70, S136

Lu, J. Y., S110

Lu, S., S70, S71

Lu, W.-Z., 534

Lu, X., S70

Lucas, J. A., S11

Lucas, P., S41

Lucey, J., S136

Ludwig, J. W., S44, S176, S178

Lum, N. L., S104

Lumbricus terrestris, soilborne diseases affected by, $\mathrm{S} 177$

Lunden, J., S168

Lundquist, J. E., S13, S145

Luo, M., S71

Luo, Y., S71

Lupien, S. L., S167

Luster, D. G., 616, 920, S71, S191

Lutzoni, F., S136

Luz, E., S71

Lycopersicon esculentum (see also Tomato): transformed, regeneration, $\mathrm{S} 104$

Lynch, S. C., S35

Lysobacter enzymogenes, antibiotic from, biocontrol, S128

Ma, B., S71

Ma, H.-X., 534

Ma, L.-J., S161

Ma, Z., 709, S71

Maas, A., S23

Maccarone, L. D., S71

MacDonald, J. D., S127

MacDonald, W. L., S8

MacGuidwin, A. E., S159

Machado, C., S36

Machado, J. E., S72

Machado, M. A., 1092

Machbash, Z., 1404

Mackenzie, M., S145

Mackenzie, S. J., S72, S92

Mackey, D., S45, S151

Macrophomina phaseolina, on vegetables, Jordan, S46

Macrosteles sp., watercress yellows phytoplasma transmission by, Hawaii, S14

Madden, L. V., 186, 616, 951, 1355, S4, S76, S85, S91, S96

Maffia, L. A., S44

Magarey, R., S145

Magnaporthe spp.

$-M$. grisea: appressorial development, transcriptional analyses, S86; on barley, whole genome expression analysis, oxygen species, S31; MPLC2 and MPLC3 genes, molecular characterization, S24; on rice, dipeptidase encoding, $\mathrm{S} 61$; on rice, Korean strain, genome analysis, $\mathrm{S} 106$; on turf, azoxystrobin resistance, $\mathrm{S} 71$; on weeds, pathogenic specificity, S45

-M. oryzae: on Oryza sativa, light effect, S66; on rice, $\mathrm{CO}_{2}$ effect, 425; on rice, inoculation methods, 346; on rice, parasexual recombina- tion, 746; on rice and wheat, genetic analysis, 480

Mahaffee, W. F., S39, S168, S169, S170

Mahoney, N. E., 369, S99

Mahovic, M. J., S9

Mahuku, G. S., S72

Maiorino, G., S97

Maize (see also Corn)

-aflatoxin resistance, USA-Africa collaboration, S16

-Aspergillus flavus and Fusarium verticillioides, competition, S30

-Aspergillus infection and stress, profile, S71

- fumonisin production, oxylipin biosynthetic pathway, S38

- fusaric acid, wilt toxin, S7

— gray leaf spot, resistance components, 593

-resistance, genetic architecture, mini-review, 120

-southern leaf blight: quantitative resistance, 221; resistance loci, inbred line population, 1067

Maize mosaic virus, glycoprotein, in insect cells, S122

Majerczak, D. R., S45

Makalowska, I., 920

Maldonado, S., S124

Malek, E., S188

Maliogka, V. I., 622

Malkus, A., S72

Mallik, I., S174

Malnoy, M., S86, S176, S180

Malpica, J., 274

Malvick, D. K., S52, S63, S146, S174

Management

-bacterial speck, plant activators, S176

-risk assessment, Florida certificate, S114

Manceau, C., S41

Mango

—malformation, Fusarium spp., symposium, 667

-malformed inflorescence, phyllody, cover photo, June

- volatile metabolites from, disease detection, S181

Man In T Veld, W. A., S72

Manjunath, K. L., S163

Mansfield, M. A., S63

Mansouri, S., S72

Manulis-Sasson, S., S85, S122

Manuscript preparation, author's guide, 7

Marasas, W. F. O., 667

Marbán-Mendoza, N., 1046

Marchand, G., S73, S178

Marcon, A., S123

Marek, S., S29, S57, S65

Marin, F. R., 1009

Markell, S., S73

Markovits, T., 771

Marois, J., S67, S82

Maroon-Lango, C. J., 460, S73

Marques, L. R., S46, S73

Marquet, X., S26

Marrero, G., S58

Marrone, P., S156

Marshall, B., S129

Marshall, D. S., S33

Marshall, M. M., S73

Marta, D., S124

Martin, B., S19

Martin, F. N., 336, 920, S74, S100, S117, S134, S146

Martin, G., S151

Martin, J., S30

Martin, K. J., S153

Martin, M. J., S74, S92, S123

Martin, R. R., S63, S112, S116

Martin, S., S18, S27

Martin, T. J., S44

Martin-Duvall, T. M., S65 
Martinez, C., S6, S7, S18

Martínez, M. C., 320

Martínez-Priego, L., 274

Martinez-Ramirez, J., S74, S94

Marutani, M., S74

Marzani, C., 689

Massart, S., 80

Massey, D. A., S180

Massman, J., S82

Massoumi Alamouti, S., S113

Masunaka, A., 934

Mata, X., S164

Matheron, M. E., S74, S169

Mathieu, T., S41

Matsuda, Y., 967

Matthews, B. F., S104, S191

Matthews, M. M., S21

Maughan, P. J., S112

Mauricio-Castillo, A., S77

Maxwell, D. P., S32, S79

May, G., S137

Mayama, S., 480

Mayer, F. W., S100

Maymon, M., 542

Maynard, C. A., S104

Mayton, H., S74, S180, S186

Mazurek, S. A., S74

Mazzola, M., S53

Mbofung, G. C., S75

Mbofung, G. M., S132

McBeath, J., S23

McCallister, J., S51

McClung, A., S54, S75, S111

McCook, S., S143

McCormick, S. P., S4

McCray, E. B., S25

McCreight, J. D., S25

McCuiston, J. L., S75

McDonald, B. A., 234, 941, 1214, S2, S128, S129

McDonald, V. T., S75

McEvoy, J. L., S75

McEvoy, P. B., S18

McGhee, G. C., S75

McGovern, K. B., S76

McGovern, R. J., S114, S187

McGrath, M. J., S82

McGrath, M. T., S76, S177, S180

McInnes, B., S74, S123

McKay, A., S167

McKee, B., S167

McKellar, M., S49, S109

McKenry, M. V., 608

McKinley, N. D., S92

McLaughlin, P., S186

McLaughlin, S. T., S166

McMahon, M., S71, S191

McManus, P. S., 709, S43

McMillan, R. T., S76

McMullen, M., S174

McNellis, T. W., S76

McPherson, R. M., S27

McRoberts, N., S76

McSorley, R., S120, S187, S188

McSpadden Gardener, B. B., 145, S11, S100

Mead, A., 1009

Medicago truncatula (see also Alfalfa)

- Phoma medicaginis, resistance sources in SARDI core collection, 1330

- plant defense signaling and pathway interactions, S81

Meeks, G. C., S64, S180

Meentemeyer, R., S144, S145

Mehl, H. L., S76

Meira argovae, on citrus rust mite, toxic secretion and $\mathrm{pH}, \mathrm{S} 92$

Mela, L., 560

Melaleuca quinquernervia, biocontrol with pathogens and insects, S96

Melampsora spp.: distribution in North America,
PCR for study, S15; on poplar, comparative genomics, S35

-M. larici-populina, on poplar, alternate host, genetic diversity, 1027

$-M$. medusae, on poplar, genetic structure, intercontinental, S34

Melanin, ophiostomatoid fungi, perithecial development, S113

Melcher, U., S19, S77

Melhus Graduate Student Symposium, S147

Mello, A. F., S77

Meloidogyne spp.: multiplex detection, 1255

-M. graminicola, geographic diversity, variability, S182

-M. hapla: genome sequence, clade IV, S149; on Onobrychus viciifolia, tolerance, S168; on potato, Vydate application, S176; proteome computing, S148

$-M$. incognita: abamectin for suppression, seed treatment, S34; on cotton, Fusarium oxysporum relation, 727 ; lethal temperature, S120; on maize, phenylalanine ammonia lyase, S79; Paecilomyces lilacinus as antagonist, gall colonization, S60; on pearl millet, resistance, $\mathrm{S} 188$

-M. partityla, on pecan, nickel deficiency, Georgia, S86

Melotto, M., S77

Melouk, H. A., S24, S77

Melzer, M., S77

Menck, C. F. M., S136

Mendez-Lozano, J., S5, S38, S67, S77, S103

Mendieta, J. R., S88

Meng, B., S77

Meng, Y., S180

Menge, J. A., S167

Mengistu, A., S78

Menkir, A., S16

Mentha spp., Vitivirus, aphid transmission, S116

$-M$. longifolia, Verticillium wilt, resistance gene analogs, S118

Menz, M., S11, S53

Menzel, W., 437

Menzies, J. G., S27, S178

Mera, J., S11

Mercado-Bianco, J., 288, 485

Mercier, J., S26, S78

Mergoum, M., 885, S108

Mertely, J. C., S72, S78, S92

Meruliporia incrassata, glyphosate herbicide, integrated control, S171

Mesocriconema xenoplax, on peach, relation to bacterial canker and chemical factors, 608

Métraux, J.-P., S150

Metz, S. P., S78

Meyer, F. W., S100

Meyer, M. M., S78

Meyer, S., S174

Mghalu, M., S79

Miano, D. W., S79

Michailides, T. J., 1142, S71, S81

Michaud, M., S7

Michelsen, P., S37

Michon, T., S84

Microsphaeropsis amaranthi

-on Amaranthus spp., bioherbicide, climatic constraints, 308

-on weed, bioherbicide, S107

Miebach, M., S54

Mikán, J., S99

Mila, A. L., 1142

Milat, M., S80, S140

Milde, L., S106

Miles, M., S8, S31

Milla, K. A., S44

Millar, L. C., S16, S79

Miller, C. L., S79

Miller, J., S141

Miller, M. E., S79, S101
Miller, M. L., S79, S95

Miller, N. L., S169

Miller, S. A., S11, S46, S79, S80

Miller, T., S25

Milus, G., S73

Mimee, B., S80

Mims, C., S158, S159

Minton, B., S185

Minz, D., 542

Mirafiori lettuce big-vein virus, on lettuce, resistance and virus sequence diversity, western USA, S124

Mitchell, T. K., S27, S31, S86

Mitchum, M. G., S120

Mizell, R. F., S80

Mizubuti, E. S., S44

Mmbaga, M., S81, S85, S157, S187

Moalemiyan, M., S181

Mock, R., S68

Model

-Asian soybean rust, severity prediction, 797

- biocontrol fungus in soil, hyphal growth, 1108

-Botrytis fruit rot of strawberry, fungicides, S92

-distance-of-spread calculations, severe weather events, S52

-fungicide spray heterogeneity, large-scale, regional spread of strains, 549

-high-threat crop pathogens, assessment rating, 616

-insect vector fitness, infectivity function, S108

- pathogen aggressiveness, quantitative evolution, two-cultivar mixtures, S129

-Sclerotinia blight, peanut, weather based, S108

- soybean rust, epidemic progress in USA, 400

-website, weather-based stem rust warning system, S93

Moens, M., 226

Moffett, P., S80

Mohamed, N., S80

Mohammadi, M., S80

Moldenhauer, K. A., S66

Moll, S., S37, S80, S135

Mollov, D. S., S15

Molnár, T. L., 1067

Moltzan, B., S47

Molyneux, R. J., 369, S99

Momol, M., S97

Momol, T., S34, S44, S46, S48, S49, S51, S53, S54, S61, S79, S80, S98

Mondal, S. N., S118, S188

Monilinia spp.

-M. fructicola: appressoria, pathogenesis role, 1372; on nectarine, appressoria, cover photo, October; on peach, QoI fungicides, S17; on peach, sulfur/propiconazole mixture, S49; on peach, survey in Georgia, S16; on stone fruit, appressorium role, 1072; stone fruit, cellular redox role, S66; on stone fruit, polymorphism of 14 alpha-demethylase gene, S90

- M. fructigena, on apple, epidemic in Hungary, S49

Montagna, R. A., S176

Monte, E., S164, S165

Monteiro, E., S81

Montero-Astúa, M., S81, S162, S164

Montesinos, E., 900

Moore, G. A., S35

Moore, W. H., S128

Moorman, G. W., S40, S178

Mor, H., S85

Mora, F., S96

Moralejo, E., S28

More, A. B., S81

Moreira, L., S81, S165

Morel, W., S31, S82

Morello, J. E., S81

Moretti, M., S140

Morgan, D., S71, S81

Morgan, G. J., 1287 
Morgan-Jones, G., S26

Morin, C., 526, S81

Moriones, E., 1263

Moriura, N., 967

Morris, T. J., S152

Moseyko, N., S160

Mosier, N., S116

Mosquera,G., 346

Motamayor, J. C., S139

Moyer, J. W., S1, S59

Mrema, F., S81, S187

Mudgett, M. B., S151

Muehlbauer, F., S23, S85

Mueller, D., S67, S82, S126

Mueller, T. A., S82

Mukherjee, S. S., S181

Mullis, S., S84, S184, S187

Mulrooney, R. P., S103

Mumma, E., S22, S82

Mundt, C. C., S18

Munjunath, K. L., S163

Muñoz, F. F., S88

Munroe, D. J., S104

Murday, E., S181

Murphy, J. A., S179

Murphy, J. F., 240

Murray, T. D., S82, S84

Muscodor albus

- antimicrobial volatiles from, potato tuber storage, S26

—biofumigation, soil, S78

- volatiles from, building mold colonization, S78

Musetti, R., 689

Mushroom

-cultivation, ecology and economics, S22

— shiitake, antibacterial agents, S184

Muskmelon (see also Cantaloupe): bacterial wilt, row cover effect, Iowa, S82

Muthukumar, V., S77

Mwangi, M., 673

Mycology

-morphology and molecules, S143

- systemic, history in USA, S143

Mycosphaerella spp.

-M. fijiensis, on banana, sequence tag, S130

$-M$. graminicola: efflux proteins, genes encoding, S11; on wheat, virulence difference between isolates, $\mathrm{S} 129$

Mycotoxins

—aflatoxicoses, outbreak in Kenya, S94

-aflatoxin: Aspergillus flavus on corn kernels, 87; clay-based interventions, S152; monitoring and management in Kenya, S152; peanuts, biopesticide for, $\mathrm{S} 153$

-fumonisin B1, translocation, corn seedlings, S131

-Fusarium on wheat, molecular breeding, S153

- maize grain, fungal detection, S153

-maize silage, dairies in Pennsylvania, S63

- toxin profile and phylogenetic groups, S131

Myers, J. R., S169

Myers, K., S18

Myrothecium spp.

-M. roridum, lethal factor encoded, S4

-M. verrucaria, bioherbicide, pesticide compatibility, S121

Mysore, K. S., 804, S5, S120

Nacobbus aberrans, on potato, risk assessment, S16

Nadal, M., S82

Nagel, A. K., S187

Nagendran, S., S82

Naidu, R. A., S83

Naik, M. K., S83

Nakaho, K., 908

Nakajima, T., 425

Nakkeeran, S., S106

Namaliu, Y., S62
Nargi, F., S83

Naswa, S., S30

Natilla, A., S56

National Plant Diagnostic Network

- entomology role, S49

- training and education program, S49

Natsuaki, T., S112

Navarre, D., S20

Navi, S. S., S83, S98

Nazarova, L. N., S102

Neate, S. M., S66

Nectarines, scab, trifloxystrobin effect, S181

Nectria galligena, on birch, girdling and perithecial production, S177

Negron, J. F., S62

Neilson, R., S171

Nell, T. A., S28

Nelson, A. H., S83, S121, S181

Nelson, B. D., S83, S174

Nelson, E. B., S22, S59, S123, S124

Nelson, M., S169

Nelson, R. J., 120

Nematodes

— community structure standard, Michigan, S12

- cropping and cover, systems in California, S122

-management practice, populations, S178

— stubby root, viruliferous, diagnostics, S171

Neotyphodium spp.: endophyte transformation, selectable markers, S129; endophytes in forage grasses, S25

-N. coenophialum, ergot alkaloid biosynthesis genes, elimination, S36

Nesmith, W. C., S185

Nester, S. E., S14

Nettleton, D., S84

Neumann, S., S60

Neveu, B., S83

New, S. L., S1

Newcomb, R. D., 838

Newman, S. E., S64

Newton, A., S129

Ngugi, H. K., S152

Nguyen, K. P., S9

Niblack, T. L., 1409, S11, S38, S84, S149

Niblett, C. L., S7

Nicaise, V., S84

Nicol, J. M., S166, S169

Nicotiana spp. (see also Tobacco): resistance genes, $N$ family, $\mathrm{S} 5$

-N. benthamiana: Citrus tristeza virus, sequences, RNA silencing, 819; Potato virus $X$ and Citrus tristeza virus sequences, cover photo, August; Pseudomonas syringae, nonhost pathogen, S120

$-N$. edwardsonii, tombusvirus resistance locus, 453

$-N$. langsdorffii, blue mold, resistance, molecular markers, S129

Nie, J., 1237, S126

Nie, X., 255

Nielsen, C. J., S28

Nielsen, R., S135

Nightingale, K., S135

Nikiforov, E. V., S102

Ning, Z., S157

Niño-Liu, D., S84

Nischwitz, C., S84, S187

Nishio, Z., S84

Nissan, G., S85

Nita, M., S85

Nitzan, N., 1097

Njambere, E., S85

Njapau, H., S94

Njoroge, S., S85, S187

Nnodu, E. C., S85

Noble, R., 1009

Noguchi, M. T., 746, S85

Noh, T., S66, S86

Noling, J. W., S78, S100
Nomenclature, USDA-ARS Systematic Botany and Mycology database, web-based information, S190

Nonomura, T., 967

Nordskog, B., S86

Norelli, J. L., S86

Norman, D. J., 876

Nowak, E., 1278

Nsa, I. Y., S112

Nugent, J. E., 709

Nunkumar, A., 1164

Nuss, D., S190

Nutter, F. W., S20, S33, S70, S86, S98, S144

Nyczepir, A. P., S86

Oak (see also Quercus rubra)

- sudden death: detection using mitochondrial genes, 336; detection and spatial modeling, forests, S144; environmental factors, S109; landscape heterogeneity effect, S145; urban forest management effect, S157

-wilt: sap beetles as vectors, S57; urban forest in Texas, S157

Oak, S. W., S52, S146

Oat

- crown rust: resistance, assessment method, S53; resistance evaluation in Intermountain West, S14

- stem rust, genetic diversity, Australia, 96

Obert, D. E., S14, S53

Obituary, Isaak Wahl, 436

Obregon, M., S164

Ocamb, C. M., S169

Ochiai, N., S90, S169, S170

Ochocki, J. E., S37

O’Donnell, K., 920, S131

Oertel, B., S10

Ofori-Adjei, D., S152

Ogata, D. Y., S86

Ogawa, Y., S74

Oh, C.-S., S181

Oh, E., S90, S170

Oh, I., S45

Oh, Y., S86

Ohki, S., S126

Oichi, W., 967

Oidium neolycopersici, on tomato, physical control, spore precipitator and dielectric insulators, 967

Ojiambo, P. S., 1168, S87

Okada, M., 425

Okori, P., S40

Okubara, P. A., 637, S170

Olano, C. T., S139

Olatinwo, R., 111, 855

Olaya, G., S71, S87

Olea europaea, olive knot, factors, 313

O'Leary, L. E., S37

Olivares-Fuster, O., S87

Olivares-García, C., 288, 485

Oliver, B., S52

Oliver, R. P., 1330

Olivieri, F. P., S69

Olmos, A., 320

Olsen, M. W., S170

Olson, B. R., S30

Olson, H. A., S87

Olson, M. E., S46, S73

Olson, S., S34, S44, S48, S51, S54, S97, S98

Olszewski, N. E., S70

Olubajo, B. A., S87

Omer, M., S70, S87

Ong, K. L., S78

Onion (see also Allium sativum)

-Alternaria spp., characterization, Puerto Rico, S162

-Artichoke yellow ringspot virus, molecular identification and cytopathology, 622

—bacterial blight, molecular epidemiology, seed production fields, 1345 
- foliar bacteria, Puerto Rico, S162

-leaf spot, Puerto Rico, S35

- soilborne pathogens, characterization, S162

-white rot, compost and Trichoderma viride for suppression, 1009

Ophiosphaerella spp

-O. agrostis, on creeping bentgrass, pseudothecia: cover photo, March; severity and overwintering, 248

-O. herpotricha, on bermudagrass, viability in winter, S119

-O. korrae, on bermudagrass, Mississippi, S92

Ophiostoma spp., on elm, DNA transposons, S15

-O. clavigerum, on lodgepole pine, methyl jasmonate treatment, S29

-O. novo-ulmi: ammonium transporter gene, S93; on elm, gene identification, S6; on elm, fruiting body genes, S31

-O. piceae, pigmentation-related genes, insertional mutagenesis, S113

Opio, F., S40

Opperman, C. H., S149

Orchid

-Cymbidium mosaic and Odontoglossum ring spot viruses, survey, S76

-Fusarium spp., Hawaii, S112

- viruses, DNA microchip array for detection, S21

Ordonez, M. E., S87

Ornamentals

- potyviruses, molecular characterization, S56

— powdery mildew, management, S157

Orostegui, A. M., S36

O'Rourke, T. A., S88

Orr, K., 1108

Orton, E., S28

Osborne, A., S100

Osborne, L., S85, S88, S91, S110

Osterbauer, N., 1416

Otrosina, W. J., S109

Otto-Hanson, L. K., S88

Oudemans, P. V., S88, S93

Owens, J. S., Jr., S147

Ownley, B. H., S25, S42, S44, S73

Oyafuso, A., S93

Özdemir, Z., S181

Pabon, A., S48, S88

Pacella, R., S34

Pacumbaba, R. P., S184

Padgett, G., S105

Paecilomyces lilacinus, biocontrol agent for nematodes, factors, S60

Pagán, I., 274

Pagano, M. R., S88

Pal, S., S34

Palmano, S., 560

Palmateer, A., S76, S89

Palomo, J. L., 900

Palou, L., S89

Pan, H., S31, S86

Panax quinquefolius (see also Ginseng)

-Cylindrocarpon root rot, iron effect, 1179

-rusted root, cause, 1243

—rusty root, phenolics and enzymes, S95

Panella, L., S141

Panijel, M., S122

Pankratova, L. F., S62

Pantoea spp.

- P. agglomerans, on gypsophila and beet plasmid-born PAI, S122; transcriptional activators, S85

-P. ananas, on agave, new in Mexico, S37

- $P$. stewartii: biofilm development, disease factor, S119; on corn, detection assay, S35; on corn, Hrp type III effector protein, S45; on corn, motility and disease, S48; on maize, motility and infection, S179; on maize, virulence and surface adhesion, S180
Paper, deterioration in industry, fungus proteases, S99

Pappu, H. R., S89

Paradornuwat, A., S67

Paret, M. L., S89

Pariaud, B., S42

Park, D., S52

Park, E., S66

Park, J., S24, S36, S52, S56, S86, S89, S90

Park, R. F., 96, 264

Park, S. (Korea), S24

Park, S.-W. (N.Y.), S66, S150

Park, S.-Y. (Pa.), 920

Park, Y., 468, S24, S58, S66, S89

Parke, J. L., S90, S169, S170

Parker, D. M., S90

Parker, P. E., S13, S14

Parker, S. R., S90

Parks, E. J., S1

Parnell, S., 549

Parra, G. R., S16

Partridge, D. E., S91

Pasche, J. S., 1097

Paspalum vaginatum. Rhizoctonia solani, biocontrol, South Carolina, S19

Pasquali, M., S91

Pataky, J. K., S20, S21

Pathogen detection, forest and ornamental landscapes, invasive, S143

Pathogen introduction, high-threat, assessment model, 616

Paul, C., S8, S91

Paul, N. D., 718

Paul, P. A., 951, S85, S91

Paulitz, T. C., 637, S105

Paveley, N. D., 680

Pavlova, G. V., S102

Pavon, C., S91

Payne, G. A., S30, S50, S53

Paz, Z., S92

Pea, root rot, phosphorous acid, S93

Peach

-bacterial canker, nematode and chemical factors, 608

- Gastrodianin anti-fungal protein, disease tolerance, $\mathrm{S} 187$

-leaf curl, environmental factors, 155

Peach mosaic virus, detection, phylogeny, molecular, 137

Peanut

- corn or cotton intercropping, microclimatic patterns, S14

-crop rotation, soil microbes, S87

-foliar and soil-borne diseases, fungicide timing, S19

-fungicide residues, bioassay, S189

-leafspot, fungicide resistance, S41

-Sclerotinia blight, fluzinam and boscalid, timing and properties, S108

-Sclerotinia minor, resistance marker, S23

— stem rot, chlorpyrifos effect, S184

Pear

- phloem-specific promoter, molecular characterization, S111

— transformation, disease resistance, $\mathrm{S} 191$

Pearson, T. C., S153

Pecan, scab, DMI fungicides, S110

Pedersen, J. F., S37

Peetz, A. B., S170

Peever, T. L., 1148, S4, S23

Pegues, M. D., S19

Pelludat, C., S92

Peltier, A. J., S174

Peng, K., S69

Penhallegon, R., S95

Penicillium spp.

-P. digitatum: on citrus, postharvest fungicides, erratum, S131; fludioxonil-resistant isolates, osmotic stress relation, S58
- $P$. expansum: airborne spores, quaternary ammonium sanitizer, S182; in soil, medium for recovery, $\mathrm{S} 182$

Penman, L., S23

Penyalver, R., 313

Pepino mosaic virus, on tomato:

-population in Spain, 274

-variants in Chile, S69

Pepper mottle virus, on pepper, Cucumber mosaic virus mixture, synergism, 240

Percy, C., S15

Perea-Araujo, L. L., S77

Pereira, I. B., S53

Pereira, R. M., S42

Peres, N. A., S72, S78, S92, S165

Perez, B. A., S124

Perez, F. G., S105

Perez, J. A., 1009

Pérez-Panadés, J., 313

Pérez-Salazar, B., S103

Periodic table

- plant pathogens, introduction, S145

-wheat and grape pathosystems, S145

Perneel, M., S146

Pernezny, K., S46

Peronospora spp.

-P. farinosa, on quinoa, resistance and diversity, S112

- P. parasitica, on Chinese broccoli, foliar fungicides, S95

-P. tabacina, on tobacco: genetics, North and Central America, S13; root infection, S129

Peronosporaceae, molecular phylogeny, challenges, $\mathrm{S} 134$

Perrier, X., 356

Perry, H., S92, S115

Perry, K. L., S3, S8

Perry, S., S49

Pertot, I., 689

Pertry, I., S135

Pest management, Armillaria root rot of Pinus radiata, 630

Peter, K., S181

Peterson, G. L., S4

Peterson, P. D., S18, S27, S143

Pethybridge, S. J., S92

Petit, A.-N., 1060

Petit, E., S170

Petrisko, J. E., S92

Petroski, R. G., S92

Pettis, G. S., S42, S105

Pfender, W., S93

Pfund, C., S111, S158

Phaeocryptopus gaeumannii, on Douglas-fir, spread in Pacific Northwest, S145

Phaeosphaeria nodorum, RNA polymerase II gene, S72

Phakopsora spp., on soybean, temperature effect, S14

-P. pachyrhizi: on soybean, detection using PCR and rain collector, $\mathrm{S} 9$; on soybean, epidemic progress and disease model, 400; on soybean, fungicide effect on germ tube and appressoria, $\mathrm{S} 67$; on soybean, fungicide timing, S17; on soybean, proteins from, spore germination, $\mathrm{S} 71$; on soybean, proteome analysis, $\mathrm{S} 22$; on soybean, spore detection, PCR assay, S9; on soybean, spore trap evaluation, S82; urediniospores, solar radiation effect, S31

Phalaenopsis spp.

-chlorotic necrosis and ringspots, tospovirus, S130

- chlorotic spots, new potyvirus, S22

-wilt, fungicides, S60

Pham, V. D., S153

Phan, N., S83

Phaseolus spp.

- P. vulgaris: angular leaf spot, gene analysis, S72; bacterial blight, strain diversity, multiple 
introductions, 1204; chocolate pod, Clover yellow vein virus cause, S169; pod rot, cultural practices, S113; Pythium and Phytophthora spp., characterization in Oklahoma, S30

$-P$. lunatus, resistance to downy mildew, screening, S103

Philion, V., S182

Phillips, D. V., S188

Phillips, M., S149

Phillips, T. D., S152

Phillips-Mora, W., S138

Phipps, P. M., S91

Phlox divaricata, carlavirus, genomic sequence, $\mathrm{S} 45$

Phoma spp., on onion, characterization, S162

$-P$. ligulicola, azoxystrobin sensitivity, Australia, S92

-P. lingam, on Brassica, blotter test protocol, S107

-P. medicaginis, on Medicago truncatula, resistance sources in SARDI core collection, 1330

- P. sclerotioides, on forage legumes, distribution in northeast USA, S125

Phomopsis spp., on Norway spruce, Gremmeniella association, 1305

- P. longicolla, on soybean: seed decay, S68; seed quality relation, seasonal progress, $\mathrm{S} 78$

Phyllosphere

-biotrophy, rust, S149

-pathogen interaction, host environment, S150

Phylogeny, Pythium and Phytophthora spp., DNA barcoding, S134

Phymatotrichopsis omnivora, on alfalfa, tolerance, S65

Physiologic specialization, pathogen speciation, sympatric race formation, life cycle, 280

Phytophthora spp.: on Austrocedrus chilensis, Argentina, S42; collection with Pythium in North Carolina, S1; detection in run-off water retention base, Virginia, S40; on European beech, geographic distribution, S181; on European beech, mefenoxam and phosphorous acid sensitivity, S121; on European beech tree, detection in New York, S121; in forest soils and streams, Oregon and California, S96; forest streams, North Carolina, S52; genome sequence data, phylogeny, S12; mitochondrial genome organization, related Straminopiles, S98; molecular markers, genomic databases, S38; nucleotide polymorphism markers, S30; phylogenetic analysis, ITS-based, S134; Pythium spp. comparison, molecular characterization, S134; races, genotypes, and varieties, analysis, S51; reverse genetic TILLING resources, S51; sporulation, asymptomatic foliage, $\mathrm{S} 28$

-P. cactorum: hybrids, ecological niches, S72; on strawberry, pyraclostrobin and azoxystrobin sensitivity, S96

- P. cambivora, on rhododendron and Pieris, new dieback, North Carolina, S185

-P. capsici: on bean, Michigan, S39; detection assay, S109; genome sequencing and population biology, S147; in irrigation water, monitoring, S173; on pepper, chemical management, $\mathrm{S} 74$; on pepper, cultivar and production system, New Jersey, S125; on pepper, mefenoxam tolerance, S186; polyphasic taxonomic analysis, $\mathrm{S} 71 ; P$. tropicalis comparison, species boundaries, S134; in soil, oospore detection, S91; soil extracts, asexual propagules, S103; on vegetable crops, Florida, S185; zoospore germination, zoxamide and dimethomorph effect, S186

- P. cinnamomi: on Fraser fir, sequence analysis, North Carolina, S42; oak, occurrence in eastern USA, S8; sporangial production and rhizosphere bacteria, S167
-P. citricola: on beech, population diversity, S83; on English walnut, phosphonate treatments, S17; on nuts and strawberry, California, S166

-P. foliorum, on azalea, leaf blight, S114

$-P$. infestans: A2 mating type, Tunisia, S55; center of origin, fungicide resistance, 1397; on potato, Acrobat MZ in management, S99; on potato, cultivar mixtures and disease pressure, 777; on potato, infection pressure and scale modeling, S108; on potato, Korean isolates, fungicide effect, S128; over-winter survival, S57; population structure, center of origin, S147; soil suppressive to, Mexico, S180; on tomato, Florida, S105; on tomato, proteomic analysis, S27

-P. nicotianae: on citrus, viroid-infected, S114; on tobacco, race $4, \mathrm{~S} 185$; on tobacco, race stability, S37

- P. palmivora, on Arabidopsis, phophite induces defense response, $\mathrm{S} 28$

-P. parasitica: aluminum sensitivity, Thielaviopsis comparison, 212; on tobacco, cutinase gene, S7

-P. phaseoli, on lima bean, environmental factors, $\mathrm{S} 103$

-P. pseudosyringae, on oak, detection using mitochondrial genes, 336

- $P$. ramorum: on camellia and rhododendron, lesion size and coverage, S114; chlamydospores, density in soil, S25; chlamydospores, detection in soil, S190; chlamydospores, detection in soil using PCR, S191; detection, DNA sensitivity, S117; detection, soil and water, retail nurseries, S120; detection in urban forest, S158; diagnosis, PCR analysis, 975; on lilac leaves, behavior in pots, S107; lineages in forests and nurseries, multiple analyses, S147; molecular markers, isolate library for detection, $\mathrm{S} 74$; on oak, detection using mitochondrial genes, 336; on oak, survey in New York, S109; perspective from southeast USA, S146; redwood-tanoak forest, dormancy, California, S35; regulation and environment, eastern USA, S146; regulation in western USA, S146; on Rhododendron, flooding effect, S43; on Rhododendron, infection potential and sporulation, S75; soil treatments, nursery beds, S127; on tanoak, detection in sapwood, S170; on tanoak, seedling roots, S90; in tanoak, xylem sapflow and sapwood conductivity, S90; TaqMan chemistry, diagnostic methods, 846; temperature extreme effect, S115; on Viburnum, Petri dish rhizotron, S191; water potential, growth and survival effect, S30; zoospores and cysts, distinguishing methods, S169

-P. siskiyouensis, in soil and water, Oregon, S97

$-P$. sojae: growth medium, metalaxyl and mefenoxam amended, S174; on Nicotiana benthamiana, glycosyl hydrolase from, S26; on soybean, Colombian isolates, S113; on soybean, detection with PCR, 1315; on soybean, field diversity in Iowa, S20; on soybean, resistance and seed treatment fungicides, S130; on soybean, WinRhizo root analysis software, S83

Phytoplasma

- classification, RFLP analysis, S192

-European stone fruit yellows, risk factors, 890

-Flavescence dorée, vector specificity, 790

- genome instability, adaptation, S135

-Malaysian periwinkle yellows, phylogeny, S56

- pepper and tomato, detection in Mexico, S103

-sequence-variable mosaics, gene clustering, S191

—web-based resource center, S191

—Western X-disease, sequence, S68

Picard, Y., 1345

Picea abies, Gremmeniella and Phomopsis association, etiology and detection, 1305
Pichia anomala, biocontrol agent for apple disease, postharvest, 80

Pierce, F., S97

Pierce, M. L., S93

Pierettti, I., 108

Pike, D., S117

Pilet, F., 777

Pine

-Austrian, systemic resistance, signaling molecules, S119

-fusiform rust: gall growth, S188; nuclear and cytoplasmic degeneration, S119

-lodgepole, dwarf mistletoe, landscape legacy in Wyoming, S145

- pitch canker, symposium, 657

Pineapple mealybug wilt associated virus, mealybug-transmitted, spread, S106

Pinon, J., 1027

Pinus spp.: blister rust, epicuticular wax and resistance, 171; Fusarium seedling blight, nurseries, 1124; tip blight, Georgia, S51

-P. monticola, blister rust: antifungal peptide gene, 164; DNA markers, 395

$-P$. radiata, Armillaria root disease, treatment area, 630

Pinzón, A. M., S38

Piquer, J., 313

Pirovani, C. P., 61

Pistacia vera, panicle and shoot blight, prediction

by Bayesian methods, 1142

Pittman, R., S77

Pivonia, S., 400, 542

Plant medicine, program at University of Florida, core emphasis, S31

Plant Pest Risk Assessment and Management, Florida certificate, S187

Plasencia, J., S93

Plasmodiophoromycetes, virus vectors, pathosystem threatens worldwide crops, S164

Plasmopara spp.

-P. halstedii, on sunflower, mycovirus, S47

-P. viticola: on grape, Alternaria alternata interaction, biocontrol, 689; on grape, chitosan and copper sulfate, 1188; on grape, Inula viscosa extract effect, 417; population structure, Greece, 501

Plata, G., S112

Plattner, R. D., S28, S95

Plectosporium tabacinum, on cucurbit, variation, New England, S183

Ploetz, R. C., 648, 653, 667, S89, S99, S138

Plourde, K., S93

Plum, sooty blotch and flyspeck, first report in USA, S64

Plum pox virus

-D and $\mathrm{M}$ types, interference, assessment, 320

-on stone fruit, survey in New York, S109

Poa spp.

- P. annua, anthracnose, mowing and rolling practices, S179

- P. arachnifera, powdery mildew, resistance in Texas, S78

Podosphaera spp.

-P. clandestina: on stone fruit, management in California, S166; sweet cherry, resistance, Pacific Northwest, S18

-P. macularis, on hop: cone infection, S39; inoculum quantification, S170

-P. xanthii: on cucurbit, fungicide resistance, S76, $\mathrm{S} 180$; on cucurbit, new races in California, S25; on melon, resistance gene Pm-1, S113; on pump-

kin, quinoxyfen sensitivity, New York, S177

Pokharel, R. R., S182

Poland, T., S158

Polashock, J. J., S88, S93

Poling, S. M., S122

Polston, J. E., 447

Pomegranate, gray mold, anifungal treatments and CA-storage, S89 
Pomella, A. W. V. 61

Ponciano, G. P., S93

Pond, E., S167

Pope, J., S33

Populus spp., rust, alternate host effect, genetic diversity, 1027

Porchas, M., S74, S169

Porter, D., S160

Porter, L. D., S93

Posos-Ponce, P., S74, S94

Postharvest pathology

-Alternaria citri on citrus, mutation analysis, 934

-apple disease controlled by Pichia anomala, 80

-Botrytis cinerea and Rhizopus stolonifer, chlorine effect on viability, S6

- fruit orientation, ultraviolet light-C treatment, decay resistance, $\mathrm{S} 110$

- potato tuber decay, detection with PCR method, 1037

Postman, J. D., S116

Postnikova, E. (Md.), S94

Postnikova, E. N. (Neb.), 1270

Potato

-Alfalfa mosaic virus, molecular detection, 1237

- aspartic protease secretion, glycosylation role, S88

-Colletotrichum coccodes, variability and vegetative compatibility groups, 1097

- disease resistance protein, Ran signaling pathway, S80

-late blight: cultivar mixtures, disease pressure, 777; mapping populations, resistance, 574; multi-genotype allelic mining, S15; phosphonate fungicides, S186

- phosphite effect, resistance, S69

- Rhizoctonia diseases, cropping system effect, 68

- scab: cystosorus production, characterization, 1157; genetic variation in USA, 1363

- silver scurf, control in storage, S43

- sodium metabisulfite effect on pathogens, S7

- soilborne diseases, crop rotation and cover crops, S64

-tuber decay: detection with PCR method, 1037; storage potential prediction, S58

Potato latent virus, Canadian isolate, detection, S126

Potato leafroll virus, readthrough protein, functions, S181

Potato virus A, detection, molecular protocols, S126

Potato virus $X$, resistance, protein-mediated, gene silencing role, 1175

Potato virus $Y$

—nucleotide polymorphism, S99

—on tobacco, salicylic acid suppression, 255

- tuber infection efficiency, yield, S8

Potyviridae, Ranunculus asiaticus host, four species, 560

Potyviruses, seed transmission, epidemiology, S132

Poussier, S., 346

Powell, A. J., S31, S94

Powell, W. A., S104

Powers, K. S., S40

Powers, T., S17

Prangé, T., S140

Prasad, P. S., S83

Prasad, R. D., S83

Prathuangwong, S., 1230, S179

Pratt, P. D., S96

Pratt, R. C., 593

Pratt, R. G., S94

Pratylenchus spp.

$-P$. penetrans: soil distribution, four field crops,

226; soil infestation, bioassay hosts, S44; on soybean, effect on Heterodera spp., S10

$-P$. thornei, on wheat, resistance, $\mathrm{S} 171$

Pretorius, Z. A., 1164
Pribbenow, C. M., S158

Price, E. W., S160

Price, J. A., S94

Prichard, T. L., S17

Probst, C., S94

Proctor, R. H., S28, S95

Professionalism

- lab management, lessons from principal investigators, S159

— student grievances, avoidance, S159

—-syllabus components, S159

-teaching emphasis, job importance, S158

Proffer, T. J., 709, S32

Prospero, S., 1337

Prunus spp.

- P. cerasifera, leaf scorch, California, S47

- $P$. domestica, plum pox virus, genetic transformation, $\mathrm{S} 107$

- $P$. persica, brown rot, appressoria, role in pathogenesis, 1072

-P. salicina, Plum pox virus, D and $\mathrm{M}$ types, interference, 320

Pruvost, O., 1345

Pryor, B. M., S24, S75, S116, S132

Pscheidt, J. W., S95, S170

Pseudomonas spp.: on canola, biocontrol, S12; corn and soybean, rhizosphere abundance, farming practices, S100; detection, PCR analysis, S128; strain genomic diversity, Turkey, S9

-P. chlororaphis, biocontrol agent, transcriptional regulator, $\mathrm{S} 106$

$-P$. fluorescens: antifungal metabolite, soilborne pathogen suppression, S170; on broccoli, biological control, 408; 2-4-diacetylphloroglucinol production by, rhizosphere colonization, 751

-P. savastanoi, on olive, factors, 313

-P. syringae: on Arabidopsis, immune defense regulator, S151; on brassica, outbreak in South Carolina, S121; genomes, PPI website, S68; genomic islands, S148; Hrp type III secretion system, role of delivery, S81; on peach, nematode and chemical factors, 608; on tobacco, Gac two-component system, S74; on tomato, defense suppression, molecular basis, S151; on tomato, transcriptional activators, S8; type III effectors, tomato susceptibility, S151

Pseudoperonospora cubensis, on watermelon, resistance sources in US plant introductions, S63

Pseudotsuga menziesii, damping-off and root rot, seedlings, 1124

Pseudozyma flocculosa

-biocontrol fungus, cyp1 gene, S73

- ecological studies, GFP technology, S83

Publication

—academic career development, factors, S158

-mentor training, merits, S158

Puccinia spp., on cereals, modeling, Russia, S102

$-P$. coronata, microsatellite library, S27; on oat, virulence frequencies in USA, S20; phylogenetic analysis, S112

-P. crupinae, on Crupina vulgaris, variability, $\mathrm{S} 17$

-P. graminis: aerial transport, detection, early warning system, S173; on oat, Australian population diversity, 96; on wheat, race TTKS resistance, $\mathrm{S} 55$

-P. jaceae, on yellow starthistle, biocontrol in California, S36

-P. lagenophorae, on Senecio vulgaris, tolerance, 718

$-P$ polysora, on maize, resistance, plant introductions, S21

-P. punctiformis, on Cirsium arvense, systemic infections, insect-transmitted spores, 813

$-P$. sorghi, on corn, virulence spectrum, S180

$-P$. striiformis, on wheat: epidemic in USA, S23; molecular and virulence differentiation, S73

$-P$. triticina, on wheat: pathotype distribution and cultivars, 264; population genetics in Asia, S62; Russia, S130; on wheat, world-wide collection, S87

Pudasaini, M. P., 226

Punja, Z. 468, 1179, S15, S21, S41, S54, S95,

S98, S119, S170

Purcell-Miramontes, M., S156

Putnam, M. L., S63, S79, S95

Pyne, M. T., S13

Pyrenophora tritici-repentis, on wheat:

—characterization in Ohio, 1355

—race 3, resistance gene mapping, 885

-races in Australia, S4

Pyricularia grisea, on ryegrass and kikuyugrass, diversity in California and Nevada, S28

Pythium spp.: on bean, cropping system, S40; on carrot, mefenoxam sensitivity, S45; dampingoff, microbes suppressive to, S22; intraspecific variability, S146; major crops in Uganda, S40; population biology, selfing and outcrossing, S146; pyraclostrobin activity against, root dysfunction, S60; soil, cereal-based cropping system, PCR quantification, S105; on soybean, in Arkansas, S100; on wheat, PCR for identification, 637; zoospores, chlorine management, S64

-P. crypto-irregulare, new species, S178

-P. myriotylum: biocontrol, S25; Monarda for biocontrol, S73

-P. oligandrum: glycoprotein elicitor, induced resistance, 908; rhizosphere compatibility and tomato grey mold biocontrol, S65

- P. ultimum, on corn and cucumber, host perception and colonization, S123

Qandah, I., S95

Qin, Q. (Texas), S117

Qin, Q.-M. (Calif.), 582, 1380

Qu, F., S152

Qu, X. S., 1157

Quarantine, identification of bacteria, microarray technology, S92

Quercus rubra (see also Oak): Phytophthora infection, S8

Quesada, J. M., 313

Quesada, L. M., S38

Quinn, A., S141

Ra, D., S66

Rabinowicz, P. D., S70

Rachmilevitch, S., 299

Rademaker, J. L. W., 876

Radopholus similes, on anthurium, chemical control, S24, S108

Rafael Mallaupoma, Z. C., S84

Rahman, M., 1179, S54, S95, S170

Rain forest, Brazil, new fungus, S12

Raina, R., S20, S95

Raina, S., S20

Rajasekaran, K., 87

Ralstonia solanacearum

-bacterial aerotaxis role, hosts, $\mathrm{S} 128$

- peroxidase gene, characterization, S36

- proteins, alternative type II secretion system, S131

-race 3 biovar 2, gene identification, S25

-race 4 biovar 4, in Zingiberacae and Costaceae, S89

-on semi-aquatic weeds, Florida, S51

-on tomato, cover crops, S54

Ramirez, H., S72

Ramirez, P., S96

Ramirez-Prado, J. H., S138

Ramos, A., S81

Randall-Schadel, B., S79, S161

Randoux, B., 1278

Rangel, E., S163

Ranunculus asiaticus, viruses of, Potyviridae, 560

Rao, I., S59 
Raspberry mottle associated virus, epidemiology, S116

Rast, H., 137

Rathayibacter toxicus, on ryegrass, genetic diversity, 1270

Ravensdale, M., S96

Rayamajhi, M. B., S96

Razavi, M., S96

Read, J. C., S78

Ream, W., 105

Rebollar-Alviter, A., S96

Recknor, J., S84

Recognition, evolutionary dynamics, molecular, S137

Records, A. R., S148

Reddy, M. S., S122

Redinbaugh, M. G., S56, S122

Redlin, S. C., S79

Redondo, E., S132

Reeleder, R. D., 1243

Reeser, P. W., S96, S97

Reglinski, T., S125

Reichenbach, H., S153

Reid, J. B., S88

Reignault, P., 1278

Reilly, C. C., S86, S97

Reinsel, M. D., S45

Reis, R. F., S118, S188

Reitz, S. R., S97

Rekoske, M. M., S141

Remus-Borel, W., S97

Renard, D., 1278

Renault, D., S97

Replogle, A., S120

Resende, R. O., 1263

Resistance

-Arabidopsis to crown gall, VirE1 mediation, 105

-barley to spot blotch, loci mapping, 699

-beta-cyanolanine synthase as marker, plant activator, 908

— citrus to leprosis, heritability, 1092

- creeping bentgrass to dollar spot, 808

- crosstalk and salicylic acid pathway, S150

—induced, historical perspective, S150

-maize to: gray leaf mold, 593; southern leaf blight, inbred lines, 1067; southern leaf blight, quantitative traits, 221

- Medicago truncatula to Phoma medicaginis, SARDI core collection, 1330

-Nicotiana edwardsonii to tombusvirus, locus introgression, 453

-nonhost, virus-induced gene silencing, S120

- Phytophthora sojae on soybean, metabolomics and RNA gene silencing, S150

-Pinus monticola to blister rust, DNA markers, 395

-Pinus strobus to blister rust, wax role, 171

- quickness vs. strength, S93

- salicylic acid, defense role, S150

-SGT1 requirement, S120

- tobacco to Potato virus $Y$, salicylic acid induced, 255

-Tobacco mosaic virus, salicylic acid and methyl salicylate, S150

- tomato to: Tomato chlorosis virus and Tomato spotted wilt virus, synergism, 1263; Tomato yellow leaf curl virus, evaluation scale, 1404

-wheat to: Fusarium head blight, recombinan inbred population, 534; powdery mildew, gene characterization, 496; powdery mildew, loci mapping, 784; tan spot, race 3, gene mapping, 885

Restrepo, S., S18, S38, S113

Rethwisch, M. D., S116

Reuven, M., 771

Reviewers, acknowledgment, 4

Rey, M., S164, S165

Rey, P., S65, S97
Reyes, H., S71

Rhexocercosporidium sp., on ginseng, rusted root, 1243

Rhizoctonia spp.: binucleate, lectins, S79; on peanut and wheat, infection cushion, S24; on potato, cropping system effect, 68

-R. solani: AG-3, protection by glucan, S124; on bean, subgroups, sequence analysis, S40; biocontrol with Streptomyces, S63; on cowpea, plant date effect, South Carolina, S114; on paeonia, biocontrol with Trichoderma, S65; on rice, $\mathrm{CO}_{2}$ effect, 425; on rice, defense transcriptome, S118; on rice, gene profiles, S55; on rice, host-selective toxin, S16; RNA and DNA elements, S6

Rhizosphere, oomycete, diversity, S59

Rho, H., S24

Rhodes, L. H., S6

Rhodococcus fascians

- on herbaceous perennials, PCR detection, S79

- pathogenicity strategies, S135

Rhynchosporium secalis, on barley:

-fertile crescent not center of origin, 941

—pathogen evolution, S2

- selection during disease cycle, 1214

-field populations, detection, S2

-host specialization, multilocus genealogy, S128

Rice

-bacterial blight and bacterial leaf streak, transcriptional profiling, S84

-bacterial leaf blight: monogenic resistance gene, S86; resistance genes in Korea, 867

-blast: field resistance in Arkansas, S66; fungicide resistance, $\mathrm{S} 43$; inoculation methods, 346; parasexual recombination, 746; $\mathrm{Pi}$-ta-mediated disease resistance pathway, S54

-blast and sheath blight, $\mathrm{CO}_{2}$ effect, 425

- cell death and resistance, RNA binding protein, S117

-Magnaporthe oryzae, wheat isolates compared, 480

— sheath blight, Rhizoctonia solani variability, S83

-Xanthomonas oryzae, $P R$ gene expression, $\mathrm{S} 93$

Rice hoja blanca virus, resistance, molecular analysis, $\mathrm{S} 18$

Richard, E. P., S43

Richards, G., S60

Richardson, P. A., S40, S51

Rick, S., S74

Riegel, D. A., S6

Riga, E., S97, S171

Rigling, D., 1337

Riley, I. T., 1270

Riley, M., S85, S159

Riley, R. T., S13

Rinehart, T. A., S185

Rios, J. C., S28, S97

Rioux, S., S10

Ripoll, D., S57

Rippetoe, C., S51

Ristaino, J., S13, S98

Ritchie, D. F., S59

Ritchie, L., S97, S98

Rivard, C. L., S98

Rivas Sanvicente, M., S93

Rivera, C., S81, S162, S163, S164, S165

Rivera, L. I., S162

Rivera, V., S141

Rivera-Soto, F., S103

Rivera-Vargas, L. I., S35, S162

Rivoal, R., S166

Rizzo, D., S30, S35, S90, S96, S160

Robène-Soustrade, I., 1345

Robert, V., S133

Roberts, D. P., S53

Roberts, M. R., S6

Roberts, P. A., 727

Roberts, P. D., S98, S105, S185, S188
Roberts, S. J., 735

Robertson, A., S20, S70, S86, S98

Robertson, C., S82

Robertson, D., S53

Robertson, L. A., 1067

Robertson, N. L., S98

Robinson, A. F., S11

Robinson, T. L., S101

Robles-Gomez, J., S74, S94

Rochon, D., S152

Rodrigues, V., 1092

Rodriguez, A., S164

Rodriguez, C. M., S165

Rodriguez, G., S98

Rodríguez, M., 900

Rodriguez-Alvarado, G., S99

Rodríguez-Jurado, D., 288

Rogers, J. D., S168

Rogers, P. M., S99

Roh, J., S45

Rojas, A., S99

Rojas, M. R., S45, S130

Rokas, A., S137

Rokhsar, D. S., S160

Rolland, M., S99

Rolón, D., S99

Rolshausen, P. E., 369, S99

Romero, G., S105

Romero, L., S18

Romero Montes, G., 1397

Rooney-Latham, S., S33, S99, S168

Roper, M., S100, S136

Rosales, M., S89, S132

Rosas, J. C., S2

Rose

- downy mildew, air circulation for control, S114

- powdery mildew: milk fat and soybean oil emulsions, S4; silicon effect, S28

-yellow mosaic, filamentous virus, S70

Rose, J. C., S27

Roselyne, C., S57

Rosenberger, D. A., S100, S182

Ross, D. S., S40

Ross, K., 453

Rossi, V., 155

Rosskopf, E. N., S100

Rossman, A., S133, S143

Rosso, M. L., S100

Rost, T. L., S21

Rostagno, L., 560

Rotenberg, D., S100

Rothrock, C. C., S100

Rothrock, C. S., S10, S113

Rott, P. C., 33, 1081

Roudet-Tavert, G., S84

Roumagnac, P., 1345

Rouse, D. I., S159

Roy, A., S101

Roy, G., 819

Royer, M., 33, 1081

Rubio, M. B., S165

Rubus spp., viruses, Costa Rica, S165

Rueda-Puente, E. O., S95

Ruelas-Ayala, R., S38, S67, S77

Rugh, A. L., S100, S182

Ruiz, O. F., S101

Rumbou, A., 501

Ruocco, M., 181

Rupe, J. C., S100, S185, S188

Rupestris stem-pitting-associated virus, on grape, cDNA clones, $\mathrm{S} 77$

Rush, C., S3, S4, S5, S56, S94

Rush, M. C., S43

Russo, N. L., S101

Rutge, N., S118

Rutger, J., S54

Rutherford, B. A., S28

Rutherford, M. A., 663

Ruz, L., 900 
Ryan, R., S136

Ryu, C., S120

Saad, A. T., S34

Saadatmand, A. R., 1046

Sabaratnam, S., S57

Saborio-R, G., S165

Sacco, M., S80

Sadkovsky, V. T., S102

Saha, S. K., S187

Sahin, E., S169

Saito, K., S84

Saitou, Y., 378

Salami, A. O., S101

Salamon-Kozubowska, J., S101

Salcedo, C. I., 313

Saldana, R., S79, S101

Saleh, A. A., 1021, S104

Salus, M. S., S32

Salzberg, S. L., S70

Samokhina, I. J., S102

Samuels, G. J., 195, 432

Sanchez, M. J., S15

Sanchez-Rangel, D., S93

Sanders, F. H., S64

Sanin, S. S., S102

Sanina, A. A., S103

Sanità di Toppi, L., 689

Sanogo, S., S103

Sanssené, J., 1278

Santamaria, L., S103

Santos-Cervantes, M., S67, S103

Saracchi, M., S140

Sasaki, N., 378, S112

Saude, C., S103, S104

Sauve, R. J., S104

Sauvion, N., 890

Savary, S., S145

Savka, M. A., S150

Scala, F., 181

Scatinok, O. O., S62

Schaad, N. W., 616, 1270, S52, S67, S94, S105, $\mathrm{S} 130$

Schaeffer, B., 264

Schardl, C. L., S34, S36, S129, S136

Scheef, E., 926

Scheffer, R. J., S104

Schell, M. A., S131

Scherm, H., 1168, S49, S87

Schiff, N. M., S123

Schilder, A., S57, S104, S174

Schilling, J. S., S182

Schizaphis graminum

- transmission of polerovirus and luteovirus, regulation, 828

—vectoring luteoviruses, proteomics, S127

Schmale, D. G.. (Va.), S104

Schmale, D. G., III (N.Y.), 1021

Schmalz, T., S182

Schmidt, L. S., S17

Schnabel, G., S16, S49, S184, S187

Schnable, P. S., S37

Schneider, J. H. M., S140

Schneider, K. E., S179

Schneider, K. T., S104, S191

Schneider, R., S22, S82, S105

Schneider, S. M., S166

Schnell, R. J., S139

Schoedel, B., S119

Schoelz, J. E., 453, S5

Scholthof, H. B., S152

Scholthof, K.-B. G., S143

Schomaker, C. H., 226

Schroeder, K. L., 637, S105

Schuenzel, E., S105

Schuhmann, S. O., 1108

Schully, K. L., S105

Schultz, D. C., S105, S185

Schultz, M. H., 876
Schulze, D. G., 130

Schumann, G., S160

Schwarz, E. M., S148

Schwartzburg, K. A., S105

Sclerotinia spp.: on chickpea, diversity in

California, S85; exotic and endemic species, hybridization in Alaska, S124; on lettuce, drop, population structure, 1322; on lettuce, irrigation and bed width effects, $\mathrm{S} 125$

$-S$. homoeocarpa: on bentgrass, model type, S58; on creeping bentgrass, dollar spot resistance, 808 ; on golf turf, fungicide sensitivity, S62; on turf, genetic structure and fungicide sensitivity, S55; vegetative compatibility, AFLP analysis, S185

$-S$. minor: mycelial compatibility groups, aggressiveness, S50; on peanut, oxalate oxidase gene for resistance, $\mathrm{S} 91$; on peanut, resistance sources, S77

-S. sclerotiorum: on bean, white mold resistance, S88; on canola, dispersal in North Dakota, S95; carpogenic germination, soil texture, S46; cell wall degrading enzymes, recombinant antibodies, S127; on lettuce, spatial patterns in Arizona, S24; population structure, Washington, S168; proteome-level analysis, S127; on rape, fungicides, S69; recombinant antibody technology, tolerance, S1271; sclerotia inhibited by Monarda, S44; sclerotium formation, Sclerotium rolfsii comparison, S94; on soybean, light effect, S174; on soybean, resistance, S174; on soybean, resistance evaluation technique, S10

Sclerotium spp.: on garlic, control strategy, S61; microherbicide for Canadian fleabane, S50; on Trifolium repens, microherbicide in lawns, S50

$-S$. rolfsii: overwintering in North Dakota, Iowa, North Carolina, and Georgia, S126; sclerotium formation, gene identification, S112

Sconyers, L. E., S186, S188

Scott, J. B., S106

Sechium edule, phytoplasma, Costa Rica, S165

Sechler, A., S52, S94, S105, S130

Sechler, K. E., S191

Secor, G., S141

Seed assay, magnetic capture hybridization, real time PCR, S55

Seedborne pathogens

-research gaps, industry perspective, S132

- seed transmission and risk analysis, epidemiology, S161

Seem, R. C., S6, S19, S29, S86, S177, S183

Seifers, D. L., S44, S106

Seifert, K. A., S41, S133

Seijo, T. E., S92

Seipke, R., S135

Selin, C., S106

Semancik, J. S., S118

Sémétey, O., 790

Senecio vulgaris rust, native and alien, tolerance, 718

Sentelhas, P., S81

Seo, M., S106

Septoria sp., on wheat, world germplasm test, S62

- S. musiva, on poplar, histopathology, S183

$-S$. passerinii, on barley: mapping resistance genes, S66; molecular mapping and gene selection, 993

- S. tritici, on wheat, Russia, S103

Serdani, M., S171

Sessa, G., S85

Sether, D. M., S106

Sewake, K., S24, S108

Seyb, A., S106, S182

Shabana, Y. M., S107

Shackel, K. A., 608

Shah, D. A., S180, S182

Shah, F. A., S30

Shamoun, S., S107, S155
Shaner, G. E., 496, S28, S85, S91

Shanklin, J., S57

Shao, J., S190, S191

Shebelut, C. W., S153

Sheedy, J. G., S171

Shelman, T., S123

Sheng, H., S82

Shepherd, C. P., S92

Shepherd, L. M., S35, S107

Sherwood, R. W., S27

Sherwood, T. A., 447

Shew, B. B., S14, S50, S59, S108

Shew, H. D., 212, S37, S185

Shi, A., S187

Shi, X., S192

Shibata, D., 908

Shields, E. J., 1021, S104

Shier, W. T., S2

Shigaki, T., S168

Shim, H., S61, S86

Shim, W., S24, S38

Shimizu, K., 967

Shin, M. S., 867

Shiraishi, T., S74

Shishkoff, N., S25, S107, S190, S191

Shriver, J. M., S98

Shugart, H., S7

Sibbald, S., S107

Siew, F., S36

Sigler, A. A., S4

Sikora, R., S60

Silue, D., S79

Silva-Rojas, H. V., 860, 1046

Sim, J., S60

Simini, M., S107

Simko, I., S74

Simmons, R., S167

Simpfendorfer, S., S15

Sims, A. L., S123

Singer, M., S153

Singh, D. (Ind.), 308

Singh, D. P. (NSW), S107

Singh, P. (Ark.), S118

Singh, P. (N.Y.), S55, S66

Singh, P. K. (N.D.), 885, S108

Singh, R. P., 784

Singh, S. P., S148

Sinn, J. P., S76

Sipes, B. S., S24, S108

Sirococcus clavigignenti-juglandacearum

- on beetle fecal pellets, viability, S178

—on butternut, mortality, S182

Sisson, A. J., S82

Sisterson, M. S., S108

Sit, T., S151

Sivasithamparam, K., S33, S71

Skaria, M., S114

Skelsey, P., S108

Sledge, M., S65

Slinski, S. L., S183

Smart, D. R., S14, S18, S64, S90, S113, S129, S176, S180, S182

Smiley, R. W., S167, S171

Smith, B. J., S189

Smith, C. A., S118

Smith, D. A., 308

Smith, D. L., S108

Smith, D. M., 828

Smith, D. R., S109, S110

Smith, J. (Mich.), S12

Smith, J. A. (Minn.), 171, S72

Smith, K. P., 993

Smith, M. D., S37

Smith, P., S121

Smith, S., S74, S188

Smith, T., S174

Smyth, T. J., 212

Snape, J. W., 680

Snook, M. E., S7 
Snover-Clift, K. L., S109

Snyder, N., S126

So, B., S58, S66

Sobolev, I., 460

Sobral, B., S161

Soika, E., S116

Soika, M. D., S116

Sokolov, U. G., S102

Sokolski, S., S137

Solanaceous crops, fungal and oomycete pathogens, microarray detection, S129

Solarization

-damping-off effect, South Carolina, S187

-methyl bromide fumigation comparison, S187

- soilborne organisms, multi-year effect, South Carolina, S187

Solheim, H., 1305

Solomon, M., 299

Somai, B., S106

Somers, D. J., S153

Someya, N., S85

Sommerhalder, R. J., 234

Son, S., S109

Song, E., S24, S66, S89

Song, F., 1052

Song, J., S109

Sorghum

-Fusarium spp., resistance and lignin content, S37

-Fusarium and Alternaria spp., grain colonization, S37

Soriano, S., 771

Soto, M. J., S109

Soule, M. J., S83

Sourdille, P., 784

Soybean

-Asian rust: in Brazil, epidemiology, S33; detection in Brazil, S29; Rpp1-mediated resistance, S104

- begomovirus detection, Mexico, S77

-brown stem rot, genotypes in North America, S174

-brown stem rot and sudden death syndrome detection using PCR, S52

- carbon dioxide and ozone effect on diseases, S32

-charcoal rot, resistance screening method, S88

- cyst nematode, sudden death syndrome, resistance, S185

-cyst nematode and Fusarium solani, interaction, factorial experiments, 1409

—diseases, forecasting models, yield loss, S105

- foliar diseases, 2005 Iowa growing season, S98

- fungicide seed treatments, North Dakota, S173

-Fusarium solani, early root infection, S38

- green stem disorder, stink bug and fungicide, S48

-mapping tools, diseases in Iowa, S86

-root and stem rot, detection with PCR, 1315

-rust: epidemic progress, disease model, 400; epidemiology, 1164; fungicide management Georgia, S186; fungicide timing, S82; network for 2005, S185; resistance development in Nigeria, S8; Rpp1-mediated resistance, analysis, S191; sentinel plot, field monitoring, Georgia, S188; severity prediction, rainfall models, 797; South Africa, 804; Syngenta spore trap project, $\mathrm{S} 188$

- Sclerotinia stem rot: field inoculation method, S52; molecular markers, bulk segregan analysis, $\mathrm{S} 91$

- sudden death syndrome: Fusarium and Heterodera interaction, 763; Minnesota, S63; nematode density, monoculture, S125; nematode and fungus interaction, specificity, S126

Spaine, P., S109

Sparks, A. N., S84

Sparks, D., S128

Speciation, sympatric host race formation, life cycle, 280

Speck, J. L., S1

Sphaeropsis spp.

- S. pyriputrescens, conidial germination, moisture duration, S61

$-S$. sapinea, on Austrian pine, systemic resistance, S34

Spiegel, S., 460

Spiers, J. M., S186

Spinach

-downy mildew, homozygous resistance, S12

-markers for traits, genomic BAC library, S115

Spiroplasma spp.

-S. citri, genetic diversity, assessment, S77

-S. kunkelii, genomic variation, S19

Spongospora subterranea

-on potato, cystosorus production, genetic analysis, 1157

-Potato mop-top pomovirus vector, Costa Rica, S164

Spotts, R., S18, S168, S171

Sprenkel, R., S97

Spring, O., S47

Spröer, C., S153

Spruce

-sapstain, bioprotection with Ceratocystis resinifera, 526

-top dieback, in Norway spruce, December cover

Squash, wild and hybrid populations, gene flow, S178

Srizhekozin, J. A., S102

Stack, J. P., 1108

Stackebrandt, E., S153

Stagonospora nodorum

- genetic variation, north central USA, S3

-mating types, recurring reproduction, 234

-on wheat: distribution in Ohio, 1355; major resistance genes, $\mathrm{S} 108$

-on winter wheat, North Carolina, 860

Stahl, D., S141

Stalpers, J., S133

Stander, J. R., S111

Stanosz, G. R., S109, S110, S137, S183

Starner, V. R., S114

Starr, J. L., S34, S79

Steadman, J. R., S2, S40, S88

Steddom, K. C., S4

Steenkamp, E. T., 667

Steenwerth, K., S90

Stefani, F. O. P., S137

Steffenson, B. J., 699, 993, S12, S20, S110

Stein, J., S85, S88, S91, S110

Stelly, D. M., S11

Stensvand, A., S110, S183

Stephenson, M. G., S27, S184

Stes, E., S135

Stevens, C., S110

Stevens, M. R., S25, S112

Stevenson, K. L., S110

Stevenson, W. R., 1037, S58, S99

Stewart, J. E., 1124, S111, S178

Stiles, C., S101, S159

Stinner, D. H., S11

St. Martin, S. K., S174

Stockwell, V. O., S171

Stone fruit

-brown rot, appressorium role in pathogenesis, 1372

-replant disease: soilborne bacteria, California, S167; soilborne fungi, associations, California, S166

Stone, J., S136, S145, S170

Stone, L. J., S4

Stoner, M. F., S171

Straminipiles, phylogeny, mitochondrial DNA, S134

Strausbaugh, C. A., S111

Strawberry

— chlorine effect on decay, S7
-Muscador effect on growth, S78

-Strawberry latent ringspot virus, genomic analysis, S116

-Trichoderma for biocontrol, methyl bromide alternative, S164

Streptomyces spp.: pathogen inhibition, Lower Rio Grande Valley, S39; phytotoxin thaxtomin, blue light-specific regulation, S57; on potato, genetic variation in USA, 1363; on potato, thaxtomin biosynthesis, S55; on wheat, endophytic root colonization, $\mathrm{S} 80$

$-S$. ipomoeae: on sweetpotato, bacteriocin analysis, S105; thaxtomin $\mathrm{C}$ biosynthetic gene cluster, cloning, S42

-S. scabiei, on potato, suberin effect, S36

-S. scabies, virulence loci, S135

Stringher, L., 689

Strizhekozin, U. A., S102

Strutz, D., S91

Sturbaum, A. K., 1397

$\mathrm{Su}, \mathrm{C} ., \mathrm{S} 23$

$\mathrm{Su}, \mathrm{H} ., \mathrm{S} 43$

Subbarao, K. V., 582, 1380, 1322, S117, S125

Sudarshana, M. R., 819

Sudarshana, P., S75, S111

Suenaga, K., 784

Sugar beet

-Aphanomyces root rot, agricultural waste lime effect, S123

-Cercospora leaf spot, pyraclostrobin for, adjuvants, $\mathrm{S} 60$

- cyst nematode, suppression by fungi in field plots, 855

- Rhizoctonia solani, cyto-histopathology, S82

Sugarcane

—aflatoxin, Texas, S38

-brown rust, soil properties and yield loss, S43

-leaf scald: albicidin biosynthesis gene variation, 33; pathogenicity of strains in Guadeloupe, 1081

Sugarcane yellow leaf virus, distribution in Costa Rica, S165

Sugawara, T., S112

Sugio, A., S151

Sulc, R., S6

Sullivan, M. J., S185

Sultana, V., S167

Summerbell, R. C., S72

Summy, K. R., S186

Sun, G., S31

Sun, Q., S111, S191, S192

Sun, W., S111

Sundin, G. W., 709, S32, S75, S147, S175

Suppressive soil, beet-cyst nematode suppression by fungi, 855

Surujdeo-Maharaj, S., S111

Susaimuthu, J., S112

Sutera cordata, ilarvirus, molecular characterization, S73

Sutherland, M. W., S15

Sutton, T. B., 982, S5

Sutton, W. C., S96, S97

Svanella-Dumas, L., S132

Švihra, P., S157

Svircev, A. M., S179

Sweetpotato

—begomoviruses, sequence variability, S79

-Rhizopus soft rot, Bio-Save 11LP and 10LP, S32

Sweetpotato chlorotic stunt virus, phylogenetic analysis, $\mathrm{S} 1$

Swenson, E. M., S112

Swett, C. L., S112

Syagrus romanzoffiana, symptoms of new disease, Florida, S185

Synchytrium solstitiale, bioherbicide on yellow starthistle, S122

Sysak, R. W., S104

Szabo, L. J., S9, S112, S173 
Szmulewich, Y., 771

Sztejnberg, A., S92

Szurek, B., S41

Tabiki, T., S84

Taguchi, F., S74

Taiwo, M. A., S112

Takach, J. E., S112

Takahashi, H., 517, 908

Takahashi, T., S112, S126

Takenaka, S., 908

Tall fescue, endophyte, nematotoxicity of alkaloids, S7

Tally, A., S17, S167

Tamba, H., 480

Tambong, J. T., 637, S146

Tanaka, K., 480

Tanaka, N., 967

Tang, J.-L., S136

Tanguay, P., 526, S107, S113

Taphrina deformans, on peach, environmental factors, 155

Tapiero, A., S113

Tarver, G., S157

Tatineni, S., S41

Taxonomy

- pathogen regulation by trait or nomenclature, S154

— plant virus, recent developments, S154

—plant virus list, USDA-APHIS, historical perspective, S155

-regulatory challenges, APHIS perspective, S154

-regulatory developments, Japan, S155

- virus and bacterial pathogen, PPQ form 526 S155

-virus classification challenge, implications for plant health, S154

Taylor, J. H., S113

Taylor, J. T., S125

Taylor, T. V., S113

Teaching

-DelsGate, functional genomics, lab course, S40

- fungal biotechnology and biochemistry, S160

- fungi as friends and foes, S159

-mushrooms and undergraduates, S160

- personal response system, Illinois, S28

- plant pathology in Jesuit education, S160

—plants, parasites, and people, S159

_plants, plagues, and people, S159

- science and society, undergraduate program, S160

—undergraduate courses, S159

-web-based instructional materials, effects, S32

Tedford, E., S167

Teixeira, A. M., S113

Teixeira, H., S44

Tejeda, S., S105

Temple, S., S85

Temple, T. N., S171

Tenney, A., S173

Tenney, J., S9

Teraoka, T., 908

Teubig, P., S174

Thakur, R. P., S83

Thannhauser, T., S27, S39, S127

Thaveechai, N., S67

Thébaud, G., 890

Thielaviopsis spp.

-T. basicola, aluminum sensitivity, Phytophthora comparison, 212

$-T$, paradoxa, on agave, base leaf spot and black rot, S74

Thieme, F., S135

Thies, J., S114, S180, S188

Thomas, C. S., S168, S169

Thomas, D., S31, S114

Thomas, J., 680

Thomas, S. L., S114

Thomas, T. P., S114
Thompson, D. (Canada), 137

Thompson, D. C. (N.J.), S114

Thompson, D. F. (Calif.), S26

Thompson, I. A., 130

Thompson, J. F., S114

Thompson, J. P., S171

Thomson, S., 926

Thuillier, E., S65

Tian, D., S71

Tian, L., S107

Tilletia spp., seed diseases, epidemiology, S132

-T. indica, on wheat: field distribution, S5; susceptibility stages, 962; teliospore dispersal, S4

Tillman, B. L., S41

Timmer, L. W., S72, S118, S165, S188

Timper, P., S188

Tirilly, Y., S65

Tisserat, N., S13, S17, S64

Tiwari, B. S., 299

Tjosvold, S. A., S114

Tobacco (see also Nicotiana spp.)

- bacterial pustule, hypersensitivity, pectic lyase homolog, 1230

-blue mold, fungicides and acquired resistance, S180

-Potato virus $Y$, salicylic acid suppression, 255

-tombusvirus resistance, introgression of locus, 453

—virus control, planting date and imidacloprid, S27

Tobacco mosaic virus, movement protein, function analysis, S109

Todd, J. W., S41

Togninia fraxinopennsylvanica, on grape and ash, California, S168

Toler, J. E., S187

Tolin, S. A., S79

Tomaso-Peterson, M., S92, S115

Tomato (see also Lycopersicon esculentum)

- bacterial canker, seed transmission, S132

-bacterial spot, management with fungicides and bacteria, $\mathrm{S} 98$

-bacterial wilt: acibenzolar-S-methyl treatment, S44; biorational compounds, greenhouse, S54

-bacteriophages, survival factors, S53

-begomoviruses, PCR for detection, 517

-Botrytis blight, volatile emission, S54

-Botrytis cinerea, botanical extracts for control Mexico, S95

-Clavibacter, Pseudomonas, and Xanthomonas spp., PCR assay, S181

-disease control, resistance pathways, S14

-Fusarium wilt, Trichoderma for suppression, S117

-late blight, genes, near-isogenic genotypes, S18

-management, grafting and multi-strategies, S98

-Pepino mosaic virus, population in Spain, 274

- postharvest pathogens, chlorine dioxide control, S9

- powdery mildew, physical control, precipitator and dielectric insulators, 967

- Pseudomonas spp., field management, S11

- spotted wilt, management with oils and films, S97

-Streptomyces spp. for disease control, S48

— viral diseases in Italy, integrated management, S34

Tomato chlorosis virus

—on tomato, Mexico, S5

-Tomato spotted wilt virus interaction, resistance breakdown, 1263

Tomato mottle virus, silencing suppressor, satellite DNA, S45

Tomato spotted wilt virus

-new host and location, S187

- on peanut, soilborne fungi relation, S59

—on tobacco, timing applications, S184 -on tomato, pepper and cabbage, reassortment, S1

Tomato yellow leaf curl virus

-on Capsicum spp., symptomless hosts, 447

-on tomato: in Mexico, S38; resistance evaluation, 1404

Tombusvirus, forest water drainage, New Zealand, S181

Tomlinson, A. N., S115

Tomlinson, J. A., 975

Tooley, P. W., 336, S74, S115

Torabi, M., S96

Torrance, R. L., S84

Torres, C., S92

Torres, R., S65

Tosa, Y., 480

Toth, I., S96

Toubia-Rahme, H., 993

Toussaint, V., S182

Toxins, TNT, soil characteristics, S107

Toyoda, H., 967

Toyoda, K., S74

Traquair, J. A., S48

Travers, S. E., S37

Travis, J. W., S115, S118, S179

Traw, M. B., S149

Tredway, L. P., S60, S115

Trently, D. J., S44

Trethowan, R., S169

Trichoderma spp.: formulations, horticultural application, S164; mechanism overview, symposium, 190; molecular biology, plant interaction, symposium, 181; systematics, sexual state, and ecology, symposium, 195, 432; systemic resistance induced by, factors, symposium, 186; transcriptomics, plant protection usefulness, S165

-T. atroviride, cell-wall degradation enzyme, profiles, S23

-T. hamatum, on tomato, gene expression nodulation, $\mathrm{S} 4$

-T. harzianum: biocontrol agent, hyphal growth model in soil, 1108; metabolites, biocontrol agents, S69

-T. stromaticum, on cacao, pathogen diversity, 61

- T. virens, on cotton, biocontrol mechanism, 178

-T. viride, Allium white rot suppressed by 1009

Trigiano, R. N., S185, S186

Tripathy, S., S30

Tropical crops, Fusarium-induced diseases, symposium, 648

Trotel-Aziz, P., 1188

Tsai, C., S122

Tsaltas, D., S119, S149, S179, S180

Tsompana, M., S1

Tsuchiya, K., S85

Tubajika, K., S116

Tucker, J., S39

Tugane, T., 908

Tulek, A., S169

Tunali, B., S169

Turcotte, P., S52

Turechek, W., S39, S47, S51, S144, S164, S169

Turfgrass

-anthracnose, evolution and lineage, 46

-bentgrass and bluegrass, putting greens, anthracnose and nitrogen, S116

-bentgrass putting green, phosphonate and contact fungicides, S115

-leaf spot pathogens, bermudagrass tissue, S115

-dollar spot: heritability, 808; vegetative compatibility, Florida, S101

- gray snow mold, snow removal effect, S13

-rapid blight, irrigation water composition, S18

- snow mold, distribution in Great Lakes region and Utah, 926

Turgeon, G. B., S28

Turina, M., 560

Turini, T. A., S116 
Turnip crinkle virus, on arabidopsis, light dependent host defense signaling, S20

Tweddell, R. J., S6, S7

Twizeyimana, M., S8

Typhula ishikariensis, on cereals and grasses, linkage map, S21

Typhula spp.

-on bluegrass, chlorothalonil and snow relation, S13

-on turfgrass and wheat, pentachloronitrobenzene sensitivity, S82

-varietal distribution in Wisconsin, Utah, Michigan, and Minnesota, 926

Tzanetakis, I. E., S112, S116

Tzfira, T., S5

Uchida, J. Y., S112, S116

Uchida, R. S., S86

Uddin, W., S28, S71, S116

Ueng, P., S72

Ugen, M., S40

Ullman, D. E., 819

Umaharan, P., S111

Uncinula necator, on grape, germ plasm collection, resistance, $\mathrm{S} 178$

Underwood, W., S77

Upper, D., S93

Úrbez-Torres, J. R., S117, S172

Uribe, P., S117

Uromyces appendiculatus, on bean, virulence evolution, DNA profile, S2

Urwin, P., S149

Ustilaginales, Pseudozyma spp., glycolipid analysis, $\mathrm{S} 80$

Ustilago maydis

- cell wall degrading enzymes, smut development, $\mathrm{S} 82$

-on corn, morphogenesis and pathogenicity, S38

Vaillancourt, L. J., S10

Vaillant, N., 1060

Valachovic, Y., S90

Valadez-Moctezuma, E., 1046

Valent, B., 346

Valenzuela-García, P., S77

Valinsky, L., S122

Vallad, G. E., 582, 1380, S117

Vallone, S., 1000

Valverde, R. A., S79

Valverde-Corredor, A., 485

van den Bosch, F., 549

Van Der Puije, G. C., S117

Van Es, H. M., S44

van Henten, E., S54

Van Hoof, R. A., 1255

van Santen, E., S89

van Sluys, M., S70, S136

Varani, A. M., S136

Varga, A., 137

Varrelmann, M., 437

Vasquez, V., S164, S165

Vecchione, A., 689

Veeraraghavan, N., 920

Vega-Sanchez, M. E., S117

Vegetable, root disease management, interdisciplinary approach, S44

Vegetative compatibility groups, Verticillium dahliae, molecular variability, 485

Velez, E., S27

Velvetleaf, rhizosphere, HCN synthase DNA, detection, S6

Vendrame, W. A., S76

Venegas, J., S2

Venette, R., S143

Venturia inaequalis

-on apple: fungicide resistance, S179; genetic diversity, markers, S118

-ascospore, maturation model, S183

Venu, R., S118
Venugopal, S., S57

Vera Cruz, C. M., 867

Verbena $\times$ hybrida, viruses, S63

Verdegaal, P. S., S65

Verdier, V., S41

Vereecke, D., S135

Vereijssen, J., S140

Verkley, G., S133

Vernet, G., 1188

Vernière, C., 356

Verreet, J., S62, S140, S142

Verticillium spp., phylogenetic analysis, 582

-V. dahliae: on artichoke, diversity in Spain, 288; crops, weeds, chile, cotton, S19; on lettuce, race-specific interactions, 1380; on Pistacia vera, sclerotial germination, S8, 1046; on spinach, resistance screening, S118; vegetative compatibility groups, molecular variability, 485

Vetten, H. J., 437

Vicent, A. C., S118

Vicente, J. G., 735

Vidalakis, G., S118

Vidaver, A. K., 616, 1270, S52, S94

Viji, G., S118

Vikram, A., S181

Villalba, L., S99

Villalobos, W., S81, S162, S163, S165

Villaréal, L. M. M. A., 280

Villareal, N., S18

Villarroel, M. I., S118

Vining, K. J., S118

Virology, history, virus design, symposium, 1287

Viruses

- host factors, infection process, S84

- minimalist pathogens, protein functions, S151

— plant survey, methods, S77

- polerovirus and luteovirus, aphid transmission, genetic regulation, 828

- proteins, transmission specificity by arthropods, S152

-replication proteins, S152

-RNA, macroarray detection, S3

-RNA silencing, environmental factors, S152

-squash and pumpkin, detection in Illinois, S57

- transmission by fungi and protists, uncoating mechanism, S152

-transport, overview, Tombusvirus P19, S152

Vitis vinifera, wedge shape canker, Botryosphaeria sp., $\mathrm{S} 172$

Vlot, A. C., S150

Voegel, T., S119, S136, S172

Voegele, R., S149

Voelker, S., S90

Voeten, J. G., S104

Voglmayr, H., S134

von Bodman, S., S48, S119, S149, S150, S179, S180

Vowell, T. S., S119

Wach, M. J., S55

Waitea circinata, on bluegrass:

- characterization in USA, S28

— fungicide sensitivity, S97

Walcott, R., S55, S161

Walgenbach, P., S48

Walker, M., S26

Walker, N., S119

Walkinshaw, C. H., S119, S188

Wallis, C., S34, S119

Wally, O., S119

Walter, J., S84

Walter, S., S16

Wamishe, Y. A., S120

Wan, A., S41, S170

Wandeler, H., 813

Wang, C., 727

Wang, D. (Minn.), S19, S184

Wang, D. S. (China), 784

Wang, G., S117, S118
Wang, J., S105, S120, S152

Wang, K., S120, S187, S188

Wang, L., S121

Wang, N., S148

Wang, W. (Canada), S77

Wang, W. Q. (China), 417

Wang, X., S70, S71, S107, S120

Wang, Ying, 1315

Wang, Yuanchao, 1315

Wang, Z. L., 784

Wanner, L. A., 1363

Wanner, L., S63

Ward, J. S., S177

Ward, K., S158

Ward, T. J., S37, S131

Warfield, C. Y., S75, S185

Warner, G. F., S173

Warnock, A. E., S10

Warren, S. L., S147

Warrior, P., S155

Wasser, R. J., 120

Water, packinghouse, decay inoculum, quantification, S171

Water management

-California nurseries, S147

-horticultural crops, conservation, S147

-pot-in-pot production, monitoring system, S147

Watermelon

- Cucumber green mottle mosaic virus and Watermelon mosaic virus, detection using RTPCR, S90

- foliar diseases, biofungicides and chlorothalonil, S192

-mycorrhizae, colonization from commercial formulations, S126

-root-knot nematode, resistance, S188

—vine decline, organisms associated, Florida, S188

Watermelon silver mottle virus, serogroup, epitopes, NSs proteins, 1296

Watrin, C., S87

Watson, S. R., S121

Weaver, M. A., S15, S121

Webb, S. E., S3

Webber, J., S28

Webster, L., S12

Wechter, P., S121

Wedge, D. E., S189

Wegulo, S. N., S114

Wei, W., S111, S191, S192

Weiland, G. E., S83

Weiland, J. E., S121, S181, S183

Weiland, J. J., S141

Weingarten, R., S111

Weinthal, D., S85, S122

Welham, S. J., 680

Weller, D. M., 751

Wells, L. W., S19

Wen, X., S122

Wen, Y., S107

Werner, N. A., S183

Wery, N., S97

West, L., S122

Westerdahl, B. B., S122

Westphal, A., 763, S125, S126

Whalen, M., S93

Wheat

- crown rot: pathogenic variation, S171; resistance loci, S15

- crown and foot rot, resistance in Idaho, S123

- deoxynivalenol, functional genomics, S16

- disease tolerance, United Kingdom, 680

-dryland root rot complex, resistance, Turkey, S169

—fungicide strategies, North Dakota, S174

-Fusarium graminearum, leaf lesion analysis, digital, S33

-Fusarium head blight: air population analysis, 1021; deoxynivalenol, meta-analysis, 951; re- 
combinant inbred population, analysis, 534; seasonal variation within-field inoculum, S91

-Fusarium seedling blight, biological control, 386

—Karnal bunt, susceptibility stages, 962

-leaf rust: clonality and adaptation, S42; latent period duration, S63; pathotype distribution and cultivars, 264

-Magnaporthe oryzae, genetic analysis with rice, 480

- powdery mildew: adult-plant resistance, loci mapping, 784; major genes in USA, S33, Milsana effect on germination and host defense 1278; resistance gene, 496; silicon compound effect, S27; silicon treatments, S178; transaconitic acid in silicon, S97

-Pyrenophora tritici-repentis race 3, gene mapping for resistance, 885

-Pyrenophora tritici-repentis, Stagonospora nodorum, distribution in Ohio, 1355

-Pythium spp., soil, PCR for identification, 637

_root-lesion nematodes, yield in Oregon, S171

-root rot, Russia, S62

-speckled snow mold, resistance and fructan accumulation, S84

-Stagonospora nodorum: mating types and sexual reproduction, 234; North Carolina, 860 ; toxins and genetic analysis, S148

- take-all: disease-induced root growth, epidemiological analysis, 510; DNA soil assay, S167; spatial pattern analysis, S41; spatial patterns, S123

Wheat streak mosaic virus

-remote detection, Texas, S56

-resistance genes, near-isogenic lines, S56

-resistance sources, S44

-root growth and water efficiency, S94

Whipps, J. M., 1009

Whitcher, L., S33

White ash mosaic virus, on Fraxinus spp., flexivirus in North America, S72

White clover, biocontrol, efficacy, S50

White, F., S70, S151

White, J. L., S155

White, K. A., S152

Whitfield, A. E., S122

Whittle, E., S57

Whitwell, T., S147

Wick, R. L., S183

Wickizer, S., S188

Wicklow, D. T., S122, S153

Widmer, T. L., S122

Widrig, A. K., S70

Wiebe, W. L., S132

Wiedmann, M., S135

Wiggins, B. E., 453, S5

Wiglesworth, M., S17, S188

Wilcox, W. F., S6, S19, S131

Wildermuth, G., S15

Wildt, J., S54

Wilkinson, C., 846

Wilkinson, H. H., S137

Wilkinson, H. T., S36

Wilkinson, M. J., S138

Williams, B., S74

Williams, H., S107

Williams, J. H., S152

Williams, L. D., S131

Williams, P. E., S13

Williams, R. W., S123

Williams, W. P., S123

Williams-Woodward, J., S51, S144

Willocquet, L., S41, S123, S145

Wilson, A. D., S123

Wilson, C. E., S66

Wilson, C. L., S110

Wilson, D. M., S152

Wilson, J. A., S130

Wilson, J. P., S188
Wilson, P. C., S147

Wilson, R. A., S106

Windels, C. E., S123, S142

Windes, J. M., S92, S123

Windham, A., S185

Windham, G. L., S123

Windham, M. T., S185, S186

Windstam, S. T., S123, S124

Wingfield, B. D, 667

Wingfield, M. J., 667

Winter, S., 622

Wintermantel, W. M., 453, S124

Winton, L. M., S124

Wise, R., S84, S161

Wisler, G., S49

Wisniewski, M., S53, S86

Wolf, P. F. J., S140, S142

Wolfe, D. W., S44

Woloshuk, C. P., S53

Wolski, E. A., S124

Wong, F., S28, S47, S74, S97

Wong, S. Y., S22

Woo, S. L., 181

Wood, B. W., S86, S97

Wood decay, brown rot, oxalic acid and oxalate regulation, $\mathrm{S} 182$

Wood products, wetwood, reduction method, S127

Woodward, J. E., S189

Woody plants, latent fungal pathogens, S137

Workneh, F., S4, S94

Worland, A., 680

WormBase Consortium, S148

Wright, D., S67, S82

Wright, E. R., S124

Wu, B. M., 582, 1322, S125

Wu, S., S161

Wu, X., 1052

Wunsch, M. J., S125

Wurms, K. V., S4, S125

Wyenandt, A., S125

Xanthomonadales, genomic analyses, S136

Xanthomonas spp.: epiphyte or pathogen, S135; genome sequences, pathogenesis analysis, S70

-X. albilineans, on sugarcane: albicidin biosynthesis genes, 33; pathogenicity in Guadeloupe, 1081

-X. axonopodis: on anthurium, detection, S119; on citrus, infection factors, S14; on citrus, wind/rain effect, S13; on onion, molecular epidmiology, seed production fields, 1345; on pepper, effector gene mutation, suppressiveness in field, S59; on soybean, hypersensitivity, pectate lyase, Thailand, S179; on tobacco, hypersensitivity, pectic lyase homolog, 1230; on tomato and pepper, molecular characterization of strains, Turkey, S9

-X. campestris: on Arabidopsis, flagellin polymorphism, S111; on bean, strain diversity, multiple introductions, 1204; on bell pepper, bactericides, S64; on brassicas, isolate comparison, related pathovars, 735; on carrot, symptomless, S167; cyclic di-GMP signaling, $\mathrm{S} 136$; on pepper and tomato, genomics, S135; on Phaseolus vulgaris, genetic diversity, breeding lines, S148; on radish, lesions, cover photo, July; on tomato, HEAT-repeat protein, host interaction, S151; on tomato, Illinois and Mexico, S103; on tomato, visualization with laser scanning microscopy, S54; weed reservoirs, New York, S64, S180; on weeds, genetic diversity in California, S52

-X. euvesicatoria, X. perforans suppressing, bacteriocin, $\mathrm{S} 48$

-X. fragariae: detection, $\mathrm{PCR}$ assay, S51; on strawberry, hot-water treatment, S47

$-X$. oryzae: cellulose genes and pathogenicity, S66; host gene activation, transcription effec- tors, $\mathrm{S} 151 ; \mathrm{HpaG}_{\mathrm{Xoc}}$ protein, glycine-rich motif and cysteine suppression, 1052; lipopolysaccharide biosynthesis, chemotypes, S89; on rice, Asian and African strains, S41; on rice, pathogenicity and hrp genes, S24; on rice, population in Korea, resistance genes, 867; on rice, strain diversity in Korea, S66; secretion system, DNA microarray, S58; specific avirulence genes, S121

-X. smithii, on citrus, Korean strains, S66

-X. translucens, on asparagus, classification, 876

Xia, X. C., 784

Xiao, C. L., S61, S67, S125

Xin, J., S80

Xing, L., 763, S125, S126

$\mathrm{Xu}, \mathrm{H} ., 1237, \mathrm{~S} 126$

$\mathrm{Xu}, \mathrm{J} ., \mathrm{S} 23$

Xu, X.-Y., 496

$\mathrm{Xu}, \mathrm{Z} ., \mathrm{S} 126$

Xylella fastidiosa

-bacteriophage libraries, random peptides, S35

—on citrus, "Candidatus, Liberibacter sp.”, S68

- on coffee, distribution in Costa Rica, S165

- collections and genomic research, S133

- colony morphology, variation in Costa Rica, S164

- on elm, detection in Oklahoma, S30

- epidemiology in Costa Rica, S81

- exopolysaccharide, detection, S100

-genomics, plant pathogenesis and insect transmission, S136

-on grape: almond, or oleander, California, S47; cold therapy, mechanisms, S78; Costa Rica, S162; motility trails on culture media, S22; site-directed mutagenesis, S47; sporadic nuisance, $\mathrm{S} 163$

-isolate comparisons, Costa Rica and the Americas, S164

-leafhopper vectors: Costa Rica, S163; ecological relations, $\mathrm{S} 163$

-on pear, multigenic sequence comparison, Taiwan, S23

- pathogen description, S136

—pathway protein, secretion, S119

- sharpshooter interaction, location in foregut, S7

- strains, genomic analysis, S127

- strains and gene locus, S22

-twitching motility, genes, S180

Xylem, Clavibacter michiganensis and Agrobacterium vitis colonization, microfluidics, $\mathrm{S} 113$

Yacouba, S., S41

Yaegashi, H., S126

Yahyaoui, A., 1214, S2, S166

Yajima, B., S127

Yakabe, L. E., S127

Yamamoto, H., 934

Yamatsuta, T., S112

Yan, W., S54

Yandoc-Ables, C. B., S100

Yánez, J. M., S178

Yang, B., S127, S151

Yang, D. Q., 526, S127

Yang, S., S61

Yang, X. B., 400, 797, S29, S33, S83, S127

Yang, Y., S27

Yao, J., S68, S127, S128

Yarbrough, L. D., S169

Yasuda, N., 746

Yates, I. E., S128

Yeager, T. H., S147

Yeh, S.-D., 1296, S130

Yeh, W., S61

Yildirim, A. F., S169

Yilmaz, S., S9, S128

Yin, B., 111

Yokomi, R. K., S77 
Yoo, S., S24

Yoon, Y., S128

Yorgancilar, A., S169

Yorinori, J. T., 1000

Yoshida, T., S85

Yoshikawa, N., 378, S112, S126

Young, C., S65

Yu, F., S128

Yu, O., S150

Yuen, G. Y., S128, S154

Zablotowicz, R. M., S2

Zaffarano, P. L., 941, S128

Zaitlin, D., S129

Zala, M., 941, S128

Zaleta-Rivera, K. M., S128

Zamani, A., 164, 395

Zapater, M., S42

Zazueta, F. S., S80

Zdor, R., S6

Zee, F., S77

Zeidan, M., 460
Zelaya-Molina, L. X., 1046

Zeller, K. A., 1021, S104

Zeng, L., S117

Zerbini, M., S132

Zettler, F. W., S159

Zhan, J., 234, 1214, S2, S129

Zhang, D., S129

Zhang, F., S77

Zhang, H., S177, S178

Zhang, N., S90, S129

Zhang, Q., S118

Zhang, S. (China), 1052

Zhang, S. (Fla.), S80

Zhang, S. (Ky.), S129

Zhang, S. (N.Y.), S37

Zhang, W., 1315

Zhang, X., 534

Zhang, Y., 1243

Zhao, T. (China), S105, S130

Zhao, T. (Ky.), 326

Zhao, Y., S111, S147, S175, S190, S191, S192

Zhemchuzhina, A. A., S130
Zheng, X., 1315

Zheng, Y., S22, S130

Zhong, S., 993, S130

Zhou, G., S23

Zhou, J.-M., S150

Zhou, S., S104

Zhou, T., S68, S69

Zhou, X., S130, S192

Zhou, Y., S130

Zhu, H., S147

Zidack, N., S49

Ziems, A. D., S130

Zijlstra, C., 1255

Zimeri, A. S., S131

Zitomer, N. C., S131

Zitter, S. M., S131

Zitter, T. A., S43

Zondag, R., S147

Zuleta, M. C., S131

Zulini, L., 689

Zumpetta, C., S100

Zveibil, A., 542, 771 